\title{
Global Initiative for Asthma Strategy 2021 Executive Summary and Rationale for Key Changes
}

¿ Helen K. Reddel ${ }^{1}$, Leonard B. Bacharier ${ }^{2}$, Eric D. Bateman ${ }^{3}$, Christopher E. Brightling ${ }^{4}$, Guy G. Brusselle ${ }^{5,6}$, Roland Buhl ${ }^{7}$, Alvaro A. Cruz ${ }^{8}$, Liesbeth Duijts ${ }^{9}$, Jeffrey M. Drazen ${ }^{10,11}$, J. Mark FitzGerald ${ }^{12}$, Louise J. Fleming ${ }^{13}$, Hiromasa Inoue ${ }^{14}$, Fanny W. Ko ${ }^{15}$, Jerry A. Krishnan ${ }^{16}$, Mark L. Levy ${ }^{17}$, Jiangtao Lin $^{18}$, Kevin Mortimer ${ }^{19,20}$, Paulo M. Pitrez ${ }^{21}$, Aziz Sheikh ${ }^{22}$, Arzu A. Yorgancioglu ${ }^{23}$, and Louis-Philippe Boulet ${ }^{24,25}$

${ }^{1}$ The Woolcock Institute of Medical Research and The University of Sydney, Sydney, Australia; ${ }^{2}$ Monroe Carell Jr. Children's Hospital at Vanderbilt, Vanderbilt University Medical Center, Nashville, Tennessee; ${ }^{3}$ Department of Medicine, University of Cape Town, Cape Town, South Africa; ${ }^{4}$ Leicester National Institute for Health Research Biomedical Research Centre, University of Leicester, Leicester, United Kingdom; ${ }^{5}$ Department of Respiratory Medicine, Ghent University Hospital, Ghent, Belgium; ${ }^{6}$ Departments of Epidemiology and Respiratory Medicine, Erasmus Medical Center, University Medical Center Rotterdam, Rotterdam, the Netherlands; ${ }^{7}$ Pulmonary Department, Mainz University Hospital, Mainz, Germany; ${ }^{8}$ Federal University of Bahia, Salvador, Bahia, Brazil; ${ }^{9}$ Department of Pediatrics, Erasmus Medical Center, University Medical Center Rotterdam, Rotterdam, the Netherlands; ${ }^{10}$ Divisions of Medical Communication and Pulmonary Medicine, Department of Medicine, Brigham and Woman's Hospital, Boston, Massachusetts;

${ }^{11}$ Harvard Medical School, Boston, Massachusetts; ${ }^{12}$ University of British Columbia, Vancouver, British Columbia, Canada; ${ }^{13}$ Imperial College London, London, United Kingdom; ${ }^{14}$ Kagoshima University, Kagoshima, Japan; ${ }^{15}$ The Chinese University of Hong Kong, Hong Kong; ${ }^{16}$ Breathe Chicago Center, University of Illinois Chicago, Chicago, Illinois; ${ }^{17}$ Locum General Practitioner, London, United Kingdom; ${ }^{18}$ China-Japan Friendship Hospital, Peking University, Beijing, China; ${ }^{19}$ Department of Respiratory Medicine, Liverpool University Hospitals National Health Service Foundation Trust, United Kingdom; ${ }^{20}$ Department of Medicine, University of Cambridge, Cambridge, United Kingdom; ${ }^{21}$ Pediatric Respiratory Division, Hospital Moinhos de Vento, Porto Alegre, Rio Grande do Sul, Brazil; ${ }^{22}$ Usher Institute, University of Edinburgh, Edinburgh, United Kingdom; ${ }^{23}$ Department of Pulmonology, Celal Bayar University, Manisa, Turkey; and ${ }^{24}$ Institut universitaire de cardiologie et de pneumologie de Québec and ${ }^{25}$ Département de médecine, Université Laval, Québec, Québec, Canada

ORCID IDs: 0000-0002-6695-6350 (H.K.R.); 0000-0003-0432-2704 (L.B.B.); 0000-0002-5064-5849 (E.D.B.); 0000-0002-9345-4903 (C.E.B.); 0000-0001-7021-8505 (G.G.B.); 0000-0001-6731-9452 (L.D.); 0000-0003-2715-9890 (J.M.D.); 0000-0002-5367-5226 (J.M.F.G); 0000-0002-7268-7433 (L.J.F.); 0000-0001-8080-3812 (H.I.); 0000-0001-8454-0087 (F.W.K.); 0000-0001-5525-4778 (J.A.K.); 0000-0002-1807-3246 (M.L.L.); 0000-0002-0228-572X (J.L.); 0000-0002-8118-8871 (K.M.); 0000-0001-7319-1133 (P.M.P.); 0000-0001-7022-3056 (A.S.); 0000-0002-4032-0944 (A.A.Y.); 0000-0003-3485-9393 (L.-P.B.).

\section{Abstract}

The Global Initiative for Asthma (GINA) Strategy Report provides clinicians with an annually updated evidence-based strategy for asthma management and prevention, which can be adapted for local circumstances (e.g., medication availability). This article summarizes key recommendations from GINA 2021, and the evidence underpinning recent changes.

GINA recommends that asthma in adults and adolescents should not be treated solely with short-acting $\beta_{2}$-agonist (SABA), because of the risks of SABA-only treatment and SABA overuse, and evidence for benefit of inhaled corticosteroids (ICS). Large trials show that as-needed combination ICS-formoterol reduces severe exacerbations by $\geqslant 60 \%$ in mild asthma compared with SABA alone, with similar exacerbation, symptom, lung function, and inflammatory outcomes as daily ICS plus as-needed SABA.

Key changes in GINA 2021 include division of the treatment figure for adults and adolescents into two tracks. Track 1 (preferred) has low-dose ICS-formoterol as the reliever at all steps: as needed only in Steps 1-2 (mild asthma), and with daily maintenance ICS-formoterol (maintenance-and-reliever therapy, "MART") in Steps 3-5. Track 2 (alternative) has as-needed SABA across all steps, plus regular ICS (Step 2) or ICS-long-acting $\beta_{2}$-agonist (Steps 3-5). For adults with moderate-to-severe asthma, GINA makes additional recommendations in Step 5 for add-on long-acting muscarinic antagonists and azithromycin, with add-on biologic therapies for severe asthma. For children 6-11 years, new treatment options are added at Steps 3-4.

Across all age groups and levels of severity, regular personalized assessment, treatment of modifiable risk factors, self-management education, skills training, appropriate medication adjustment, and review remain essential to optimize asthma outcomes.

Keywords: asthma; asthma diagnosis; asthma management; asthma prevention

(Received in original form September 27, 2021; accepted in final form October 18, 2021)

əThis article is open access and distributed under the terms of the Creative Commons Attribution Non-Commercial No Derivatives License 4.0 For commercial usage and reprints, please e-mail Diane Gern (dgern@thoracic.org).

Am J Respir Crit Care Med Vol 205, Iss 1, pp 17-35, Jan 1, 2022

Copyright (C) 2022 by the American Thoracic Society

Originally Published in Press as DOI: 10.1164/rccm.202109-2205PP on October 18, 2021

Internet address: www.atsjournals.org 


\section{Introduction}

Asthma is a serious global health problem affecting all age groups (1). Its prevalence has increased in many countries, especially among children. The Global Initiative for Asthma (GINA) aims to improve the diagnosis, management, and prevention of asthma by providing an up-to-date evidencebased strategy and tools and practical resources for clinicians worldwide.

GINA was established through a 1993 collaboration between the World Health
Organization (WHO) and the U.S. NHLBI to develop a strategy for the diagnosis and management of asthma (2). The Global Strategy for Asthma Management and Prevention (GINA strategy report) has been updated annually since 2002 to provide clinicians with up-to-date, evidence-based recommendations as new evidence emerges and new therapies are approved. The GINA strategy report is under continual review by the Science Committee. GINA methodology (3) involves evaluation of new evidence identified from a twice-yearly rolling review of original research and systematic reviews (not limited to specific population/ intervention/comparison/outcomes questions), assessment of its impact on existing or new recommendations, and consideration of whether and how it should be integrated into the overall asthma management strategy. GINA is independent of industry.

This article summarizes key recommendations from the 2021 GINA strategy report (4), published in April 2021, and briefly summarizes the evidence and rationale for recent important changes.

\section{Key Recommendations:}

1. Diagnosis: In adults, adolescents, and children $\geqslant 6$ years, confirm the diagnosis of asthma before starting controller treatment, whenever possible, as it is often more difficult afterward. In children $\leqslant 5$ years, recurrent wheezing is common, but asthma is more likely if they have wheezing or coughing with exercise/laughing/crying or in the absence of respiratory infections and if they have a history of eczema or allergic rhinitis.

2. Personalized assess-treat-review cycles: Asthma management should be personalized and adjusted in a continual cycle of assessment, treatment, and review to minimize symptoms and prevent exacerbations. Consider symptom control, risk factors for exacerbations and side effects, lung function, comorbidities, self-management skills, and patient and/or caregiver goals, preferences, and satisfaction.

3. Comprehensive care: Asthma management is not "one-size-fits-all." It includes not only medication but also treatment of modifiable risk factors and comorbidities, nonpharmacological strategies, and education and skills training, particularly for inhaler technique and adherence.

4. Inhaled corticosteroids (ICS): Asthma in adults and adolescents should not be managed solely with short-acting $\beta_{2-}$ agonists (SABAs). Instead, to reduce the risk of severe exacerbations, and to control symptoms, all adults and adolescents with asthma should be treated with ICS-containing therapy: either regularly every day or, in mild asthma, with ICS-formoterol taken as needed for symptom relief. ICS-containing treatment is also recommended for all children 6-11 years with asthma: either regularly or, in mild asthma, by taking ICS whenever SABA is taken. The past distinction between "intermittent" and "mild persistent" asthma was arbitrary and does not indicate a differential response to ICS.

5. Treatment tracks: In 2021, for clarity, the Global Initiative for Asthma treatment for adults and adolescents was divided into two tracks, depending on the inhaled reliever medication. Across the five steps, treatment may be stepped up or down within a track, by using the same reliever at each step, or may be switched between tracks, according to the patient's needs and preferences:

- Track 1, with low-dose ICS-formoterol as the reliever. This is the overall preferred approach because it reduces the risk of severe exacerbations, compared with using a SABA reliever (with/without a maintenance controller), while achieving similar symptom control, similar lung function, and a lower oral corticosteroid burden. In Steps 1-2, there are additional reasons for preferring as-needed-only ICS-formoterol over as-needed SABA (alone or with daily ICS): 1) patients with "mild" asthma can have severe exacerbations; 2) adherence with daily ICS is almost universally poor in patients with mild or infrequent symptoms, leaving them at higher risk of severe exacerbations; and 3) starting treatment with SABA alone trains patients to regard it as their main asthma treatment. As-needed-only ICS-formoterol (without maintenance treatment) in Steps 1-2 should be distinguished from maintenance-and-reliever therapy $(\mathrm{MART})^{\star}$ in Steps $3-5$, in which patients also take ICS-formoterol as daily maintenance treatment. MART is also an option for children 6-11 years in Steps 3-4. ICS-formoterol should not be used as a reliever for patients taking a combination of a nonformoterol ICS-long-acting $\beta_{2}$-agonist, with/without a long-acting muscarinic antagonist.

(Continues on next page)

Supported by the Global Initiative for Asthma (GINA). GINA is supported only by the sale and licensing of its reports and figures. These recommendations were developed by GINA and are not official guidelines from the American Thoracic Society. They have not been reviewed or endorsed by the American Thoracic Society Board of Directors.

Correspondence and requests for reprints should be addressed to Helen K. Reddel, M.B. B.S., Ph.D., Woolcock Institute of Medical Research, 431 Glebe Point Road, Glebe, NSW 2037, Australia. E-mail: helen.reddel@sydney.edu.au.

This article has an online supplement, which is accessible from this issue's table of contents at www.atsjournals.org. 


\section{Key Recommendations (Continued):}

- Track 2, with SABA as the reliever. This is an alternative approach (e.g., if Track 1 is not possible or is not preferred by a patient with no exacerbations in the last year). However, before considering a regimen with a SABA reliever, consider whether the patient is likely to adhere to controller therapy. If not, they will be expsed to the risks of SABAonly treatment. For Step 1, taking ICS whenever SABA is taken is preferable to taking SABA alone.

For either track, the Global Initiative for Asthma provides an integrated approach and decision tree for difficult-to-treat and severe asthma, with add-on therapies recommended in Step 5 for severe asthma, including biologic therapy guided by the inflammatory phenotype.

6. Children $\leqslant \mathbf{5}$ years: Manage wheezing episodes initially with inhaled SABA. Consider trialing controller therapy (e.g., for $3 \mathrm{mo}$ ) if the symptom pattern suggests asthma, alternative diagnoses have been excluded, and respiratory symptoms and/ or wheezing episodes are frequent or severe.

7. Stepping up: Before stepping up treatment to control symptoms or prevent exacerbations, confirm that the symptoms are due to asthma, identify and address modifiable risk factors (including incorrect inhaler technique, poor medication adherence, environmental exposures, and multimorbidity), and provide patient education.

8. Stepping down: Once asthma is well controlled for $2-3$ months, consider stepping down gradually to find the minimum effective dose, monitoring the patient frequently. Step up again if needed.

9. Asthma action plans: As part of supported asthma self-management, provide a personalized written asthma action plan for all patients, tailored to their health literacy, so they know how to recognize and respond to worsening asthma.

10. Referral: Refer patients for expert advice if any of the following apply:

- The diagnosis of asthma cannot confidently be confirmed. For children $\leqslant 5$ years, strongly consider referral for further diagnostic investigations if there is a very early onset of symptoms, failure to respond to treatment, or features suggesting alternative diagnoses (e.g., hypoxemia, finger clubbing, failure to thrive).

- Occupational asthma is suspected.

- The patient has any risk factors for asthma-related death.

- Symptoms or exacerbations remain uncontrolled despite medium/high-dose ICS-long-acting $\beta_{2}$-agonist.

- The patient needs urgent health care or oral corticosteroids more than once a year.

- There is evidence or high risk of treatment side effects.

- Food allergy is suspected.

${ }^{\star}$ Also called single-inhaler maintenance-and-reliever therapy (SMART).

\section{Asthma Management during the COVID-19 Pandemic}

Most studies have shown that patients with asthma are not at increased risk of acquiring coronavirus disease (COVID-19) or of severe COVID-19. Advise patients to continue taking their prescribed asthma medicines, including inhaled corticosteroids (ICS), alone or in combination with a long-acting $\beta_{2^{-}}$ agonist (LABA), and biological therapy for severe asthma.

Avoid the use of nebulizers, where possible, because of the risk of viral transmission. Within healthcare facilities, follow local infection control procedures and COVID-19 testing recommendations if spirometry, peak expiratory flow (PEF) measurement, or other aerosol-generating procedures (e.g., oxygen therapy, sputum induction, ventilation) are needed.

GINA recommends COVID-19 vaccination for people with asthma, with usual precautions including checking for allergies to vaccine ingredients. Anaphylaxis to foods, insect venom, or medications is not a contraindication. Consider giving the first dose of asthma biologic therapy on a different day from the COVID-19 vaccine.

\section{Definition, Description, and Diagnosis of Asthma}

Asthma is a heterogeneous disease defined by the history of respiratory symptoms (e.g., wheeze, shortness of breath, chest tightness, and cough) that vary over time and in intensity, together with variable expiratory airflow limitation. Airflow limitation may later become persistent.

Asthma is usually associated with airway hyperresponsiveness and airway inflammation, but these are not necessary or sufficient for diagnosis. Clinical phenotypes (e.g., childhood onset vs. late onset, allergic vs. nonallergic) do not correlate strongly with specific pathological processes or treatment responses.
The diagnosis of asthma is based on a history of characteristic symptom patterns and evidence of variable expiratory airflow limitation obtained from bronchodilator reversibility testing or from other tests, such as a positive bronchial provocation test result, excessive variability during PEF monitoring, excessive variation in $\mathrm{FEV}_{1}$ between visits, or a significant increase in $\mathrm{FEV}_{1}$ after ICS treatment (see Table E1 in the online supplement). Explain to patients that often, more than one of these tests is needed (5). Evidence for the diagnosis of asthma should be confirmed before starting controller treatment, if possible, to avoid inappropriate treatment or missing other important diagnoses and because diagnosis is often more difficult later. Results from clinical examination, including chest auscultation, may be completely normal.

The concentration of fractional exhaled nitric oxide $\left(\mathrm{FE}_{\mathrm{NO}}\right)$ is higher in asthma with type 2 airway inflammation but is also higher in atopy, allergic rhinitis, eczema, and 


\section{A. Asthma symptom control}

In the past 4 weeks, has the patient had:

- Daytime asthma symptoms more than twice/week?

- Any night waking due to asthma?

- SABA reliever for symptoms more than twice/week?*

- Any activity limitation due to asthma?
Level of asthma symptom control

$\begin{array}{ccc}\text { Well } & \text { Partly } & \text { Uncontrolled } \\ \text { controlled } & \text { controlled }\end{array}$

$\left.\begin{array}{c}\text { Yes } \square \text { No } \square \\ \text { Yes } \square \text { No } \square \\ \text { Yes } \square \text { No } \square \\ \text { Yes } \square \text { No } \square\end{array}\right\}$ of these

$1-2$

of these
3-4

of these

\section{B. Risk factors for poor asthma outcomes}

Assess risk factors at diagnosis and periodically, particularly for patients experiencing exacerbations.

Measure $\mathrm{FEV}_{1}$ at start of treatment, after 3-6 months of controller treatment to record the patient's personal best lung function, then periodically for ongoing risk assessment.

\section{Having uncontrolled asthma symptoms is an important risk factor for exacerbations.}

Additional potentially modifiable risk factors for flare-ups (exacerbations), even in patients with few symptoms ${ }^{\dagger}$ include:

- Medications: high SABA use (associated with increased risk of exacerbations and mortality particularly if $\geq 1$ x 200-dose canister per month); inadequate ICS: not prescribed ICS; poor adherence; incorrect inhaler technique

- Other medical conditions: obesity; chronic rhinosinusitis; GERD; confirmed food allergy; pregnancy

- Exposures: smoking; allergen exposure if sensitized; air pollution

- Context: major psychological or socioeconomic problems

- Lung function: low $\mathrm{FEV}_{1}$, especially $<60 \%$ predicted; high $\mathrm{BD}$ reversibility

- Other tests in patients with Type 2 inflammation: blood eosinophils; elevated FeNO (in adults with allergic asthma taking ICS)

Other major independent risk factors for flare-ups (exacerbations)

- Ever intubated or in intensive care unit for asthma

- $\quad \geq 1$ severe exacerbation in last 12 months

Risk factors for developing persistent airflow limitation

- History: preterm birth, low birth weight and greater infant weight gain; chronic mucus hypersecretion

- Medications: lack of ICS treatment in patients who had a severe exacerbation

- Exposures: tobacco smoke; noxious chemicals; occupational exposures

- Investigations: low initial FEV $\mathrm{F}_{1}$; sputum or blood eosinophilia

Risk factors for medication side-effects

- Systemic: frequent OCS; long-term, high dose and/or potent ICS; also taking P450 inhibitors

- Local: high dose or potent ICS; poor inhaler technique

Figure 1. Global Initiative for Asthma assessment of asthma control in adults, adolescents, and children 6-11 years. For a version of this figure with full reference citations, please see Box 2-2 in Reference 4. P450 inhibitors include cytochrome P450 inhibitors such as ritonavir,

ketoconazole, and itraconazole. *Based on SABA (as-needed ICS-formoterol reliever not included); excludes reliever taken before exercise. For children 6-11 years, see also Box 2-3 in Reference 4. For specific risk reduction strategies, see Box 3-8 in Reference 4. "Independent" risk factors are those that are significant after adjustment for the level of symptom control. Reproduced by permission from Reference 4 (Box 2-2). $\mathrm{BD}=$ bronchodilator; $\mathrm{FE}_{\mathrm{NO}}=$ fractional exhaled nitric oxide; $\mathrm{GERD}$ = gastroesophageal reflux disease; ICS = inhaled corticosteroid; OCS = oral corticosteroid; SABA = short-acting $\beta_{2}$-agonist. 


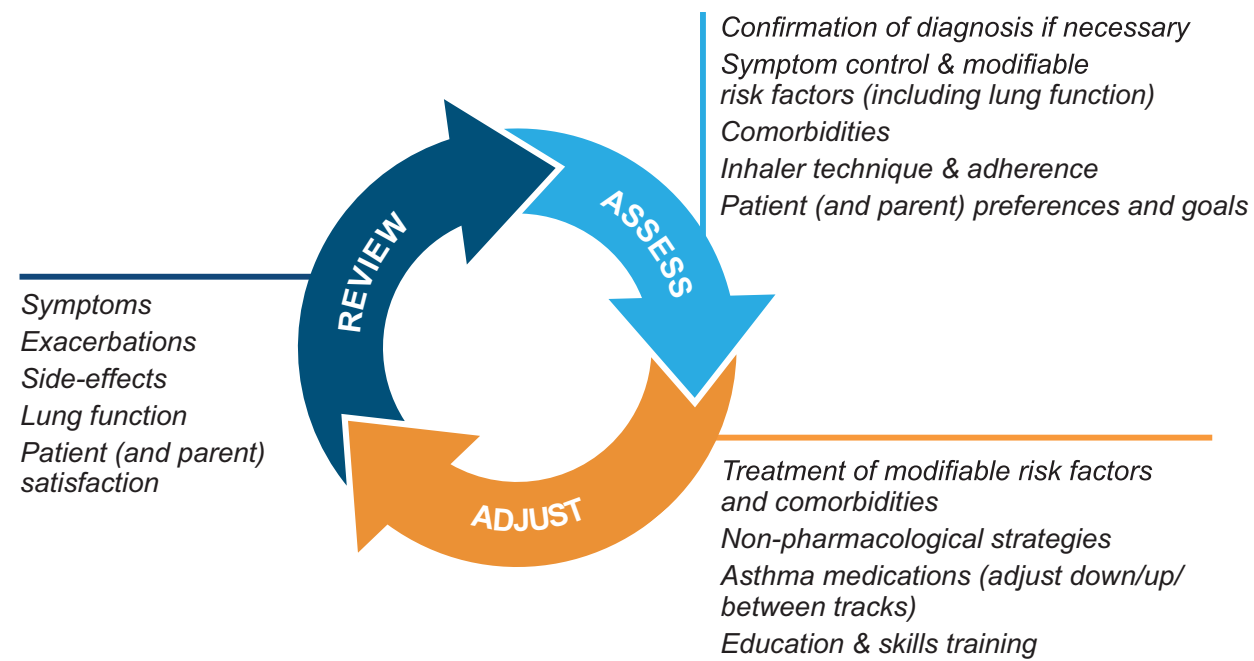

Figure 2. Personalized asthma management cycle of care. Reproduced by permission from Reference 4 (Box 3-2).

eosinophilic bronchitis, and it is lower during bronchoconstriction and in some asthma phenotypes (e.g., neutrophilic asthma). It can be increased or decreased by viral respiratory infections.

Additional strategies may be needed to confirm the diagnosis of asthma in particular populations, including patients already on controller treatment (see Box 1-3 in Reference 4), the elderly, smokers, and those in low-resource settings. The differential diagnosis of asthma varies by age (Box 1-5 in Reference 4).

\section{Assessment of Asthma}

Asthma control is defined as the extent to which the features of asthma are apparent or have been reduced or eliminated by controller treatment (6). Assess asthma control within two domains: symptom control and risk of adverse outcomes, particularly exacerbations.

\section{Symptom Control}

Assess symptom control from asthmarelated symptom frequency, night waking and activity limitation, and, for patients using short-acting $\beta_{2}$-agonist (SABA) reliever, the frequency of SABA use (Figure 1). Other symptom control tools include the Asthma Control Test (7) and the Asthma Control Questionnaire (preferably the five-item version) (8).

Rationale. Historically, the frequency of SABA reliever use ( $\leqslant 2$ or $>2 \mathrm{~d} / \mathrm{wk}$ ) was included in the composite assessment of symptom control. This distinction was arbitrary and was based on the assumption that if a SABA was used on $>2$ days in a week, the patient needed to start controller therapy or increase the dose. However, if a patient uses as-needed ICS-formoterol as their reliever on average $>2 \mathrm{~d} / \mathrm{wk}$, this is already providing additional controller therapy, so further dose escalation may not be needed. Therefore, use of ICS-formoterol reliever $\leqslant 2$ versus $>2 \mathrm{~d} /$ wk is not included in the composite assessment of symptom control. Instead, the average frequency of ICS-formoterol use over the past 4 weeks should be assessed separately when the patient's maintenance controller dose is reviewed.

\section{Risk Factors}

Assess every patient's risk of exacerbations, even when symptom control is good. Although patients with poor symptom control are more likely to have exacerbations, patients with few or no symptoms can still have severe or even fatal exacerbations, including with external triggers such as viral respiratory infections (9). Factors that increase a patient's risk of exacerbations even if they have few symptoms include one or more exacerbations in the previous year, overuse of SABA (e.g., $\geqslant 3 \times 200$-dose albuterol [salbutamol] canisters per year [i.e., average more than daily use]), inadequate ICS use (undertreatment, poor adherence, incorrect inhaler technique), some comorbidities (including obesity, chronic rhinosinusitis, gastroesophageal reflux, confirmed food allergy), a low
$\mathrm{FEV}_{1}$, a high blood eosinophil count in patients with type 2 inflammation, and major psychological or socioeconomic problems. Also assess risk factors for persistent airflow limitation and medication side effects (Figure 1).

\section{Lung Function Testing}

Record lung function at diagnosis, 3-6 months after starting treatment, and then periodically (e.g., at least once every 1-2 yr; more often in at-risk patients and those with severe asthma) to identify progressive decline. Lung function at individual visits is of limited use for guiding treatment because of its large (up to $20 \%$ ) visit-to-visit variation (10). Investigate further if there are few symptoms but impaired lung function is present, which may indicate poor perception (11) or long-term adaptation, or if there are frequent symptoms despite good lung function, which may indicate an alternative cause for the symptoms (Box 1-5 in Reference 4).

\section{Asthma Severity}

By consensus (6), asthma severity is assessed retrospectively, after at least 2-3 months of treatment, from the level of treatment required to control symptoms and exacerbations. GINA does not distinguish between so-called "intermittent" and "mild persistent" asthma because this historical distinction was arbitrary, with no evidence of a difference in the treatment response. Severe asthma is asthma that remains 


\section{Adults \& adolescents $12+$ years}

Personalized asthma management Assess, Adjust, Review

for individual patient needs

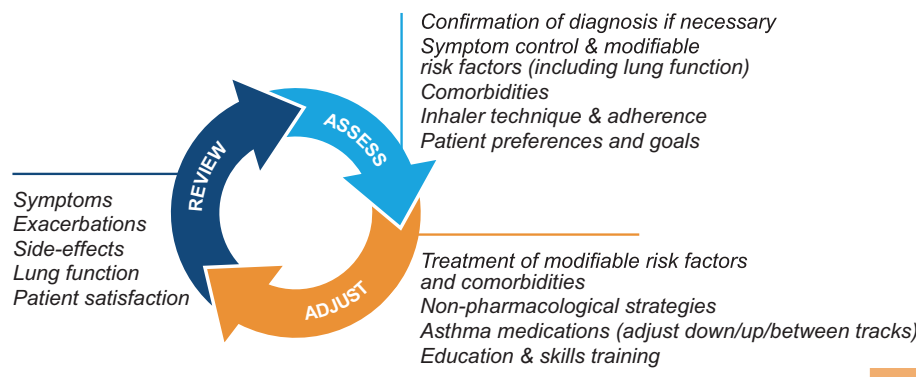

Education \& skills training

\begin{abstract}
CONTROLLER and PREFERRED RELIEVER

(Track 1). Using ICS-formotero as reliever reduces the risk of exacerbations compared with using a SABA reliever
\end{abstract}

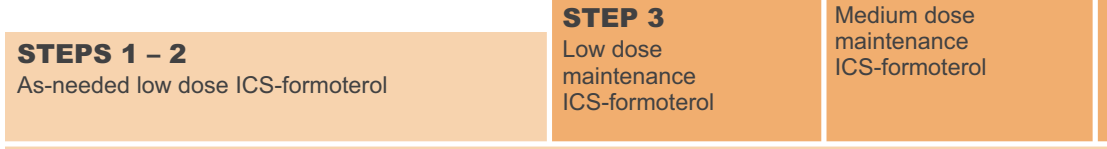

RELIEVER: As-needed low-dose ICS-formoterol
STEP 5

Add-on LAMA Refer for phenotypic assessment \pm anti-lgE anti-IL5/5R, anti-IL4R Consider high dose ICS-formoterol

\begin{abstract}
CONTROLLER and ALTERNATIVE RELIEVER

(Track 2). Before considering a regimen with SABA reliever, check if the patient is likely to be adherent with daily controller
\end{abstract} \\ Other controller options for either track}

\section{$\begin{array}{ll} & \\ & \text { STEP 2 } \\ \text { LTEP 1 } & \begin{array}{l}\text { Low dose } \\ \text { maintenance ICS }\end{array} \\ \text { Take ICS whenever } & \end{array}$ \\ General Principles of Asthma Management}

RELIEVER: As-needed short-acting $\beta 2$-agonist

\section{STEP 4}

Medium/high dose maintenance ICS-LABA

STEP 3

Low dose maintenance ICS-LABA
STEP 5

Add-on LAMA Refer for phenotypic assessment \pm anti-lgE anti-IL5/5R, anti-IL4R Consider high dose ICS-LABA

Figure 3. Personalized management for adults and adolescents to control symptoms and minimize risk. For ICS doses, see Box 3-6 in Reference 4. Reproduced by permission from Reference 4 (Box 3-5A). HDM = house dust mite; ICS = inhaled corticosteroid; LABA = long-acting $\beta_{2}$-agonist; LAMA = long-acting muscarinic antagonist; LTRA = leukotriene receptor antagonist; OCS = oral corticosteroid; SABA = short-acting $\beta_{2^{-}}$ agonist; SLIT = sublingual immunotherapy.

uncontrolled despite optimized treatment with high-dose ICS-LABA or that requires such treatment to prevent it from becoming uncontrolled (12). It is important to distinguish between severe asthma and difficult-to-treat asthma (i.e., asthma that may be uncontrolled because of other factors, such as incorrect inhaler technique, poor adherence, and comorbidities such as obesity and environmental exposures) (13).

Rationale. This definition of asthma severity works well at the severe end of the spectrum but is less useful for describing mild asthma (see TOPICs REQUIRING FurTHER RESEARCH). For example, patients with infrequent or no interval symptoms can still have severe exacerbations. This risk is reduced to a similar extent by either daily ICS treatment $(14,15)$ or by ICS-formoterol taken only for symptom relief (15), and the baseline symptom frequency does not predict the need for daily ICS $(15,16)$.
The goals of asthma management are to achieve good symptom control, relieve symptoms when they occur, and minimize the risk of exacerbations and asthma-related death, persistent airflow limitation, and side effects of treatment. The patient's own treatment goals should be identified because they may be different. Effective asthma management requires a partnership between the patient (or parent/caregiver) and healthcare providers, with shared decision-making and good communication.

Asthma management is not "onesize-fits-all" but instead should be personalized and adjusted in a continual cycle of assessment, treatment adjustment, and review (Figure 2).

\section{Assessment}

Assess not only symptom control and lung function but also the individual's modifiable risk factors and comorbidities (also called "treatable traits") (17) and patient/parent goals and preferences. Check adherence and inhaler technique frequently. Poor symptom control is associated with a much higher risk of exacerbations, but patients with apparently mild asthma or with good symptom control can still have severe or life-threatening exacerbations $(9,14,18)$.

\section{Treatment Adjustment}

Treatment adjustment includes not only changes in the asthma medication dose or type but also multidisciplinary management of modifiable risk factors and comorbidities (Section 3D in Reference 4) and nonpharmacological strategies such as smoking cessation and avoidance of indoor/ 
outdoor air pollution (Box 3-9 in

Reference 4).

For all patients, provide regular training in inhaler techniques and asthma selfmanagement, including self-monitoring of symptoms and/or PEF, and a written asthma action plan (19) (Section 3C in Reference 4). Encourage adherence with controller medication, even when symptoms are infrequent. Consider stepping down treatment when good control has been maintained for 2-3 months (Box 3-7 in Reference 4).

\section{Review}

Arrange regular medical review to identify modifiable risk factors, optimize care, and minimize the risk of exacerbations; review at least yearly (more often in patients with moderate or severe asthma), after an exacerbation, and after a treatment change. Review clinical outcomes and side effects, patient/parent/caregiver satisfaction, inhaler technique and self-management skills. Ensure the patient/caregiver has an up-todate written asthma action plan.

Rationale. The GINA strategy (Figure 2) considers not only patient characteristics that may predict a clinically important difference in treatment response but also medication access, the patient's preferences, and practical issues of cost, ability to use the inhaler, and likely adherence. The extent to which asthma treatment can be individualized according to patient characteristics or phenotype depends on the health system, the clinical context, evidence about the magnitude of potential difference in outcomes, cost, and available resources.

\section{Medications and Strategies for Symptom Control and Risk Reduction}

Asthma medications are categorized as controllers, relievers, and add-on therapies:

- Controllers contain ICS, which reduce airway inflammation, control symptoms, and reduce the risks of exacerbations (20), even in mild asthma $(14,15,21)$, and of asthma death (22). Treatment with ICS may reduce exacerbation-related declines in lung function. (23) "Maintenance" therapies are controllers that are prescribed for daily use.
- Relievers (low-dose ICS-formoterol or SABA) contain rapid-onset bronchodilators. They are used "as needed" (i.e., for quick relief of symptoms, including during exacerbations). Using ICS-formoterol as a reliever (often called an "antiinflammatory reliever" or "AIR") also reduces the risk of severe exacerbations, compared with a SABA reliever, both with $(24,25)$ or without $(15,21)$ maintenance controller treatment. SABA or ICS-formoterol is also recommended before exercise if needed to prevent exercise-induced bronchoconstriction $(26,27)$.

- Add-on therapies are mainly for patients with difficult-to-treat or severe asthma (see below).

When choosing medications, consider local guidelines, regulatory approvals, and payer criteria.

\section{Recommendation against SABA-Only Treatment}

Since 2019, GINA has recommended against SABA-only treatment of asthma in adults and adolescents after consideration of its risks and the evidence for a safer alternative (28). Instead, to reduce the risk of serious exacerbations and control symptoms, all adults and adolescents with asthma should receive ICS-containing treatment, either regularly or, in mild asthma, as needed to relieve symptoms (28). ICS is now also recommended for all children 6-11 years with asthma, either regularly or, in mild asthma, whenever SABA is taken for symptom relief.

Rationale. Although SABA is inexpensive and relieves symptoms quickly, treatment of asthma with SABA alone is associated with increased risk of asthmarelated death (22) and of urgent asthmarelated health care (20), even in patients with so-called intermittent asthma (29). Overuse of SABAs $(\geqslant 3 \times 200$-dose albuterol canisters per year) is associated with incrementally increasing risk of asthma exacerbations and mortality, including in patients treated with SABA alone (22). Regular use of SABA, even 2-4 times per day for 1-2 weeks, is associated with $\beta_{2}$-receptor downregulation, loss of bronchodilator response, increased airway hyperresponsiveness, and increased airway inflammation $(30,31)$. Importantly, from a cognitive and behavioral perspective, starting treatment with SABA alone trains the patient to regard it as their main asthma treatment, increasing the challenges for adherence with any subsequent advice to take ICS every day even when asymptomatic.

By contrast, in mild asthma, as-needed ICS-formoterol decreases the risk of severe exacerbations requiring oral corticosteroid (OCS) by $\geqslant 60 \%$ compared with SABA alone $(15,21)$, including in patients without elevated type 2 inflammatory markers (15, 32 ), with a very small average daily ICS dose $(15,16,21,33)$. Starting treatment with as-needed ICS-formoterol in patients with mild asthma addresses both symptom relief and risk reduction without the need for daily maintenance treatment.

\section{GINA Treatment Tracks for Adults and Adolescents}

There are five levels of treatment (Steps 1-5; Figure 3), with two "tracks," depending on the choice of reliever: ICS-formoterol (Track 1, preferred) or SABA (Track 2, alternative). Treatment may be stepped up or down within a track by using the same reliever at each step or may be switched between tracks.

Within Track 1, the reliever is as-needed, low-dose ICS-formoterol. This means that when a patient at any treatment step has asthma symptoms, they take lowdose ICS-formoterol for symptom relief. In Steps 1-2, this also provides the patient's controller therapy and reduces severe exacerbation risk $(15,16,21,33)$, without daily maintenance treatment. This is distinguished from maintenance-andreliever therapy (MART) in Steps 3-5, where patients take ICS-formoterol both as daily maintenance treatment and, as needed, for symptom relief (Table 1).

Track 2, with SABA reliever, is suggested where ICS-formoterol is not available or is not preferred by a patient at low risk of exacerbations (including having no exacerbations in the past year). Before prescribing therapy with SABA reliever, consider if the patient is likely to be poorly adherent with ICS controller therapy, as this increases the risk of exacerbations.

In Figure 3, additional or alternative treatments with less evidence for safety, efficacy, and/or effectiveness are shown as "other controller options."

Rationale. GINA introduced two tracks into the 2021 treatment figure for adults and 
Table 1. Differences between Current Asthma Treatment Regimens Containing an AIR

\section{Anti-inflammatory Reliever (AIR) Therapy Alone (GINA Steps 1-2)}

Maintenance-and-Reliever Therapy (MART*) (GINA Steps 3-5)
Definition

Indications

Explanation

Rationale

Combination ICS-formoterol taken as needed for symptom relief, ${ }^{\dagger}$ without maintenance therapy. Or, if not available, low-dose ICS taken whenever SABA is taken for symptom relief.

\section{Mild asthma: GINA Steps 1-2}

Whenever symptom relief is needed, the patient takes an inhaler containing a combination of a low dose of ICS and formoterol (instead of a SABA), without daily maintenance treatment.

Or, if ICS-formoterol is not available, they take a Iow dose of ICS whenever SABA is taken.

Medications and age groups studied

\author{
Budesonide-formoterol ( $\geqslant 12 \mathrm{yr}$ ). There have \\ been smaller studies with \\ beclometasone-albuterol in combination or \\ separate inhalers in adults $\geqslant 18 \mathrm{yr}$, \\ adolescents and children $\geqslant 4 \mathrm{yr}$.
}

In patients with mild asthma, as-needed-only budesonide-formoterol reduced severe exacerbations by $\geqslant 60 \%$ compared with SABA alone, with similar symptom control and lung function as maintenance ICS plus as-needed SABA.

With as-needed-only ICS + SABA in patients with mild asthma, some studies showed fewer exacerbations than SABA alone; other studies showed similar outcomes to physician-adjusted ICS treatment.

\author{
Daily maintenance ICS-formoterol. \\ PLUS \\ Low-dose ICS-formoterol taken as needed for \\ symptom relief. ${ }^{\dagger}$
}

Moderate-to-severe asthma: GINA Steps 3-5

The patient takes regular daily maintenance controller treatment with low-dose (Step 3) or medium-dose (Step 4) combination

ICS-formoterol.

PLUS

Whenever needed for symptom relief, the patient uses an inhaler containing a combination of a low dose of ICS and formoterol (instead of a SABA).

Budesonide-formoterol (ages $\geqslant 4 \mathrm{yr}$ ).

Or beclometasone-formoterol (adults $\geqslant 18 \mathrm{yr}$ ).

In moderate-to-severe asthma, MART with ICS-formoterol reduced severe exacerbations compared with the same dose or high-dose ICS or ICS-LABA plus as-needed SABA, with similar symptom control and lung function.

There have been no studies with ICS + SABA both used as MART, and some evidence suggests that taking ICS + SABA regularly may increase exacerbation risk.

Definition of abbreviations: GINA = Global Initiative for Asthma; ICS = inhaled corticosteroid; LABA = long-acting $\beta_{2}$-agonist; LAMA = long-acting muscarinic antagonist; SABA = short-acting $\beta_{2}$-agonist; SMART = single-inhaler MART

"AIR" is a term used for reliever inhalers that contain a combination of an ICS with either formoterol or albuterol. ICS-formoterol contains a combination of an ICS

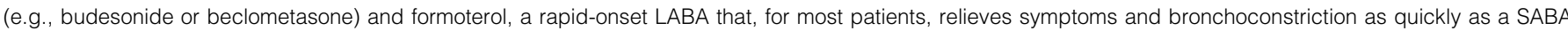
When budesonide-formoterol or beclometasone-formoterol are used as needed, a single inhalation is taken for symptom relief. If symptoms persist after a few minutes, an additional inhalation can be taken, but no more than 6 inhalations should be taken on a single occasion (four inhalations of budesonide-formoterol for

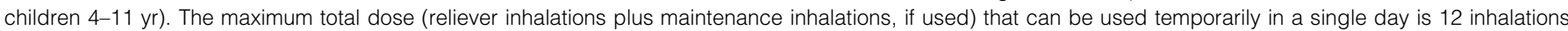
of budesonide-formoterol for adults/adolescents (total of 8 inhalations for children 4-11 yr) and a total of 8 inhalations of beclometasone-formoterol for adults. If patients need more than this, they should seek medical help the same day. Other ICS-formoterol formulations (e.g., mometasone-formoterol, fluticasone propionate-formoterol) have not been studied as antiinflammatory relievers, either alone or in MART, but could be substituted if budesonide-formoterol or

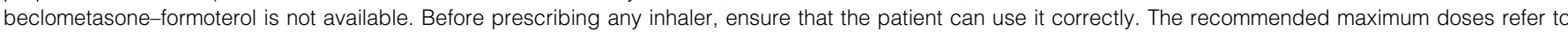
the maximum total dose that can be taken temporarily on any single day, not the expected or desirable average use. In clinical trials of as-needed budesonide-formoterol in adults and adolescents with mild asthma, patients used an average of only 3 to 4 inhalations per week of low-dose budesonide-formoterol, and $<0.1 \%$ of patients took more than 8 inhalations of budesonide-formoterol on more than 1 day during the 12 months of treatment

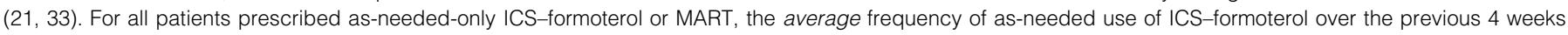

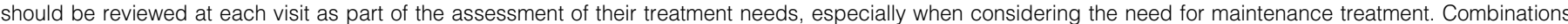

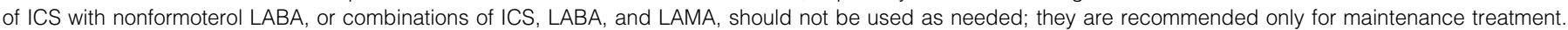
For patients using a nonformoterol ICS-LABA (with or without a LAMA), the appropriate reliever is SABA.

${ }^{*}$ Also called SMART.

${ }^{\dagger}$ For dosage details, see Table E2 and the downloadable resource in the online supplement.

adolescents (Figure 3 and Box 3-5A in Reference 4) to clarify:

- How to step treatment up or down within the different reliever options (ICS-formoterol or SABA).

- That SABA is the recommended reliever for patients prescribed maintenance nonformoterol ICS-LABA.

The Track 1 approach is preferred overall because it reduces the risk of severe exacerbations compared with using a SABA reliever, with similar symptom control and lung function, and it integrates messaging about the importance of both symptom control and risk reduction across all treatment steps, including Step 1. The figure also summarizes the main considerations for choosing ICS-formoterol or SABA as the reliever and reinforces the key elements of personalized asthma treatment. 


\section{GINA Treatment Steps for Adults and Adolescents}

\section{Steps 1 and 2, Preferred Treatment (Track 1)}

The preferred treatment for adults and adolescents with mild asthma is low-dose ICS-formoterol taken as needed for symptom relief, without maintenance treatment (Figure 3). As-needed-only ICS-formoterol is usually prescribed with a budesonide-formoterol inhaler providing a metered dose of 200/6 $\mu \mathrm{g}$ per inhalation (equivalent to a delivered dose of $160 / 4.5 \mu \mathrm{g}$ ), with one inhalation taken as needed for symptom relief (Table 1; for dosage details, see Table E2 and the downloadable resource in the online supplement). Other combination ICS-formoterol products may be suitable but have not yet been studied.

Rationale. Considerations for the recommendations at Steps 1 and 2 are interrelated. In patients eligible for Step 2 treatment, two large studies found that as-needed ICS-formoterol reduced the risk of severe exacerbations by almost two-thirds compared with SABA-only treatment (15, $21)$. Four studies ( $\sim 10,000$ patients) showed a similar or greater reduction in severe exacerbations compared with daily low-dose ICS, without clinically important differences in symptom control $(15,16,21,33)$, lung function $(15,16,21,33)$, or airway inflammation measured by $\mathrm{FE}_{\mathrm{NO}}(15,16)$ over 12 months. The primary outcome variable of one study (21) was "wellcontrolled asthma weeks," but this outcome was not considered reliable because it was based on a past definition of asthma control and was systematically biased against the as-needed ICS-formoterol treatment group, in which patients were permitted much less ICS than those on maintenance ICS before a week was classified as not well controlled. In two studies that showed a greater overall reduction in the risk of severe exacerbations with as-needed ICS-formoterol compared with maintenance ICS plus as-needed SABA $(15,16)$, no predictors of differential response were identified among many baseline characteristics, including inflammatory phenotype $(15,16)$, except for a clinically unimportant difference in the five-item Asthma Control Questionnaire in one study (16).

In Step 1, the recommendation for as-needed, low-dose ICS-formoterol for adults and adolescents with symptoms less than twice per month is supported by indirect evidence for a large reduction in the risk of severe exacerbations, compared with as-needed SABA alone $(15,21)$. Extension of this recommendation to Step 1 was also supported by several important considerations:

- Historically, recommendations for as-needed SABA alone were never supported by evidence of long-term safety or efficacy; early guidelines had assumed that patients with mild asthma would not benefit from ICS and were concerned about its risks based on experience with OCS.

- The past distinction between eligibility for Step 1 and Step 2 treatment based on symptom frequency (e.g., $\leqslant$ or $>2 \mathrm{~d}$ /wk) was arbitrary, not evidencebased.

- The use of as-needed ICS-formoterol markedly reduces severe exacerbations, compared with as-needed SABA, even in patients with SABA use less than or equal to two times per week at baseline (so-called intermittent asthma) (15).

- A single day with more than two, more than four, more than six, or more than eight doses of as-needed budesonide-formoterol reduced the short-term (21-d) risk of severe exacerbations, compared with as-needed SABA alone (post hoc analysis) (34). A similar effect was seen with ICS-formoterol MART in Steps 3-4 $(35,36)$.

- $\quad$ Even modest overuse of SABA (e.g., dispensing three or more albuterol canisters per year, i.e., average of $\geqslant 1.6$ puffs/d) is associated with an increased risk of severe exacerbations $(37,38)$ and, in one study, higher asthma mortality (38).

- Even occasional short courses of OCS (e.g., four to five courses over $7 \mathrm{yr}$ [i.e., less than one course per year]), are associated with significant short-term risks (39) and cumulative risks of long-term adverse effects such as osteoporosis and diabetes (40).

- Regular, daily, low-dose ICS treatment is highly effective in reducing asthma symptoms and risk, including in patients with infrequent symptoms (14), but poor adherence to ICS is common (41), exposing patients to the risks of SABA-only treatment.

- As-needed budesonide-formoterol is well tolerated in mild asthma $(15,16$, 21, 33).

- $\quad$ Starting treatment with SABA alone trains the patient to regard it as their primary asthma treatment.

\section{Steps 1 and 2, Alternative Treatment (Track 2)}

The alternative (non-preferred) Step 2 recommendation for adults and adolescents remains regular, low-dose ICS with as-needed SABA. The Step 1 recommendation is taking ICS whenever SABA is taken (combination or separate inhalers).

Rationale. For patients with initial symptoms twice per month or more, lowdose maintenance ICS reduces the risk of serious exacerbations by almost half compared with SABA alone (14). There is a paucity of evidence for the safety and effectiveness of as-needed concomitant ICS + SABA, as only small groups received this regimen in studies of adults $(42,43)$ and children $5-18$ years $(44,45)$. However, concomitant ICS + SABA would be preferable to using SABA alone if ICS-formoterol is not available or affordable. No data are available about the acceptability to adults of carrying separate ICS and SABA inhalers for symptom relief or on what proportion of patients would revert to SABA-only use. No data are available about safe levels of as-needed ICS + SABA use, but in one study, exacerbations were higher among patients randomized to twice-daily ICS-SABA than among those on as-needed ICS-SABA (42), consistent with risks associated with SABA overuse (38).

\section{Steps 3 and 4}

The preferred Step 3 treatment is maintenance-and-reliever therapy (MART) with low-dose ICS-formoterol $(24,25,46)$, which is approved in many countries with budesonide-formoterol and beclometasone-formoterol. For Step 4, if needed, the maintenance dose of ICS-formoterol can be increased to medium $(36,47,48)$. The doses of ICS-formoterol recommended for MART, including the maximum dose in any day, are shown in Table E2 and the downloadable resource in the online supplement. 
Rationale. In adults and adolescents with poor symptom control and one or more exacerbations in the previous year, MART reduced exacerbations and provided similar symptom control at relatively low ICS doses, compared with maintenance ICS-LABA or higher-dose ICS, both with as-needed SABA $(24,49-51)$. In open-label studies in broader populations, MART also significantly reduced severe exacerbations, with a lower average dose of ICS $(25,46)$. ICS-formoterol should not be used as the reliever for patients taking maintenance nonformoterol ICS-LABA because there are no data for efficacy and safety.

\section{Step 5}

See Difficult-to-Treat and Severe Asthma in Adults AND Adolescents, below.

\section{Choosing Initial Asthma Treatment}

When choosing the track and starting step for initial treatment (Boxes 3-4A-3-4D in Reference 4 ), consider not only the patient's current symptoms and risk of exacerbations but also practical issues, including medication access (availability and cost), inhaler technique, likely adherence, and patient preferences. Before starting, record evidence for the diagnosis of asthma, the patient's symptom control and risk factors, including lung function, and check that they can use the inhaler correctly. Provide education and skills training, and schedule a follow-up visit to assess the response (Figure 2).

During ongoing treatment, medication may be adjusted up or down within the same track (i.e., with the same reliever) or may be switched between tracks, depending on patient needs. However, for patients prescribed asneeded-only ICS-formoterol (Steps 1-2) or MART (Steps 3-5), beware of risks to the patient if their ICS-formoterol is switched without consultation (e.g., in health systems where medication substitution by pharmacists or nurses is permitted) to a combination nonformoterol ICS-LABA, as these are not suitable for as-needed use.

\section{Stepping Down to Find the Minimum Effective Dose}

When good asthma control has been achieved and maintained for 2-3 months, consider stepping down to find the lowest effective step. Do not completely withdraw ICS, except if needed temporarily while confirming the diagnosis of asthma. Adults and adolescents with well-controlled asthma while on daily low-dose controller therapy can step down to either as-needed ICS-formoterol $(16,21,33)$ or to as-needed ICS + SABA taken together $(42,43)$ (Box 3-7 in Reference 4).

\section{Stepping Up if Asthma Remains Uncontrolled}

Before considering any sustained step up, first check inhaler technique, adherence, persistent allergen exposure and comorbidities.

There is no evidence to support specific recommendations about when to increase from as-needed-only ICS-formoterol in Steps 1-2 to Step 3 MART by adding maintenance ICS-formoterol, but it should be prompted by factors such as ongoing use of as-needed ICS-formoterol on most days of the week or further exacerbations.

\section{Patients with Risk Factors for Exacerbations}

Prescribe an ICS-containing controller, preferably with ICS-formoterol as the reliever, as this reduces the risk of severe exacerbations $(15,16,21,24,25,33,46)$. Arrange review more frequently than for patients at low risk. Identify and address modifiable risk factors (e.g., smoking, overuse of SABA, comorbidities) (Box 3-8 in Reference 4). Consider nonpharmacological strategies, such as smoking cessation advice and trigger avoidance, to improve symptom control and/or reduce risk (Box 3-9 in Reference 4).

\section{Management of Exercise- induced Symptoms}

For patients with dyspnea or wheezing on exertion, distinguish between exerciseinduced bronchoconstriction and symptoms due to obesity, poor cardiopulmonary fitness, or alternative diagnoses such as inducible laryngeal obstruction. For patients with exercise-induced bronchoconstriction, prescribe ICS-containing controller treatment and advise sufficient warm-up before exercise (26). Patients using as-needed ICS-formoterol as their reliever (Track 1) can use the same medication before exercise, if needed, and do not need a SABA inhaler (27).

Rationale. For pre-exercise use by adults and adolescents, formoterol was recommended in guidelines for many years as an effective and safe alternative to albuterol (26) but is no longer promoted because of risks of LABA-only treatment. Pre-exercise ICS-formoterol avoids this risk and is as effective as daily ICS plus preexercise SABA in reducing exercise-induced bronchoconstriction (27).

\section{GINA Steps for Children Aged 6-11}

Treatment steps for children are shown in Figure 4 (Box 3-5B in Reference 4). In Step 1, for children with initial symptoms less than twice per month, taking ICS whenever SABA is taken for symptom relief is preferred over regular ICS or as-needed SABA alone. Regular, low-dose ICS with as-needed SABA is recommended in Step 2 for most children with asthma, but attention must be paid to adherence.

In Step 3, options include low-dose ICS-LABA, medium-dose ICS, or very-lowdose budesonide-formoterol MART (52). In Step 4, options include medium-dose ICS-LABA (53) or low-dose MART (Table 1; Table E2 and downloadable resource in the online supplement). For all children at Step 4, consider referral for expert advice. In children, before stepping up, consider trying other controller options at the same step.

Rationale. The addition of as-needed concomitant ICS + SABA as an antiinflammatory reliever in Step 1 for children was based on evidence from two studies in which children and adolescents were stepped down from maintenance ICS to as-needed ICS plus SABA in separate inhalers $(44,45)$ and because of likely nonadherence with daily ICS by children with infrequent symptoms. For Step 2, there is much more evidence for the safety and effectiveness of maintenance low-dose ICS, but in the real world, ICS adherence is extremely low. In Step 3, MART with verylow-dose ICS-formoterol (52) was previously recommended in the GINA report text and for consistency is now also included in the figure (Box 3-5B in Reference 4 and Figure 4). For Step 4, doubling the MART maintenance dose to $100 / 6 \mu \mathrm{g}$ (delivered dose of $80 / 4.5 \mu \mathrm{g}$ ) by instructing the patient to take one inhalation twice daily (still "low dose") was included by consensus, given the variation in ICS responsiveness between patients (Table 1; Table E2 and downloadable resource in the online supplement). 


\section{Children 6-11 years}

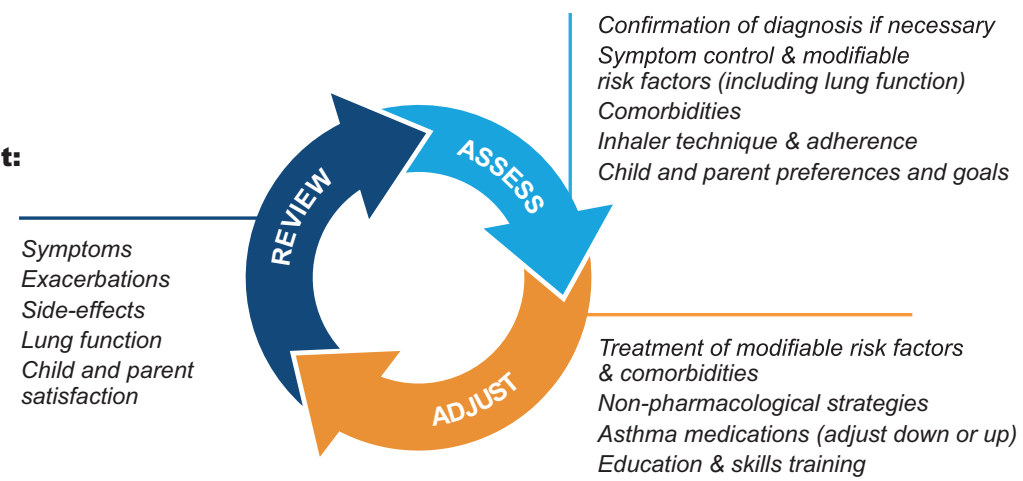

Personalized asthma management: Assess, Adjust, Review

Asthma medication options: Adjust treatment up and down for individual child's needs

\section{PREFERRED CONTROLLER to prevent exacerbations and control symptoms

\begin{tabular}{l|l}
\begin{tabular}{l|l} 
PREFERRED \\
CONTROLLER \\
to prevent exacerbations \\
and control symptoms
\end{tabular} & $\begin{array}{l}\text { STEP 1 } \\
\text { Low dose ICS } \\
\text { taken whenever } \\
\text { SABA taken }\end{array}$ \\
& $\begin{array}{l}\text { Consider daily } \\
\text { low dose ICS }\end{array}$ \\
$\begin{array}{l}\text { Other } \\
\text { controller options }\end{array}$ & \\
\end{tabular} \\ RELIEVER \\ Managing Asthma with Comorbidities and in Specific Populations}

\section{STEP 2}

Daily low dose inhaled corticosteroid (ICS) (see table of ICS dose ranges for children)

Daily leukotriene receptor antagonist (LTRA), or low dose ICS taken whenever SABA taken
Confirmation of diagnosis if necessary Symptom control \& modifiable risk factors (including lung function)

Child and parent preferences and goals

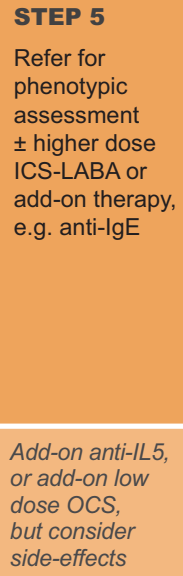

As-needed short-acting beta2-agonist (or ICS-formoterol reliever for MART as above)

*Very low dose: BUD-FORM 100/6 mcg

tLow dose: BUD-FORM 200/6 mcg (metered doses).

Figure 4. Personalized management for children 6-11 years to control symptoms and minimize future risk. For ICS doses for children, see Box 3-6 in Reference 4. For MART doses, see Table E2 and the downloadable resource in the online supplement. Reproduced by permission from Reference 4 (Box 3-5B). BUD-FORM = budesonide-formoterol; ICS = inhaled corticosteroid; LABA = long-acting $\beta_{2}$-agonist; LTRA = leukotriene receptor antagonist; MART = maintenance-and-reliever therapy; OCS = oral corticosteroid; SABA = short-acting $\beta_{2}$-agonist

Identify and manage comorbidities such as rhinosinusitis, obesity, and gastroesophageal reflux disease. Multimorbidity contributes to respiratory symptoms and impaired quality of life, and some comorbidities contribute to poor symptom control or exacerbations.

Despite general concerns about medication use in pregnancy, the advantages of actively treating asthma in pregnancy to avoid exacerbations markedly outweigh any potential adverse effects of usual controller and reliever medications (54).

For details of multidisciplinary assessment and management of asthma with comorbidities and in specific settings, see Chapter 3D in Reference 4.

\section{Diagnosis and Initial Treatment of Patients with Features of Both Asthma and Chronic Obstructive Pulmonary Disease}

Asthma and chronic obstructive pulmonary disease (COPD) are umbrella labels for overlapping heterogeneous conditions. Symptoms may be similar, and the diagnostic criteria overlap. Some patients have features of both asthma and COPD (asthma + COPD), particularly smokers and older adults. This is not a single disease entity. It includes several clinical phenotypes that are likely caused by a range of underlying mechanisms.

There are important differences in evidence-based treatment recommendations for asthma (4) versus COPD (55), with treatment with longacting bronchodilators alone (i.e., without ICS) recommended as initial treatment in
COPD but contraindicated in asthma because of the risk of severe exacerbations and death. Until more discriminatory risk factors are identified, all patients with diagnoses of both asthma and COPD should receive ICS. COPD should be managed according to Global Initiative for Chronic Obstructive Lung Disease (55) recommendations. For all patients, provide education on inhaler technique and adherence and advice about smoking cessation, immunizations, physical activity, and management of comorbidities. Refer for specialist investigations and multidisciplinary care, where possible.

Rationale. The descriptive term “asthma + COPD" is preferred because "asthma-COPD overlap" was often assumed to represent a single disease. Patients with asthma + COPD have a greater burden of symptoms and exacerbations, more impaired quality of life, more rapid decline in lung function, greater need for healthcare use, and 
higher mortality than patients with asthma or COPD alone (4). The recommendation for ICS is because several studies have shown that patients with diagnoses of both asthma and COPD are at increased risk of hospitalization or death if they are treated with LABA compared with

ICS-LABA (56-58).

\section{Difficult-to-Treat and Severe Asthma in Adults and Adolescents}

Detailed information is provided in the GINA 2021 pocket guide on difficult-to-treat and severe asthma (13), including an integrated decision tree for diagnosis and management across primary and specialist care. A brief summary is included below.

\section{Assessment and Optimization of Therapy}

Difficult-to-treat asthma is asthma that is uncontrolled despite medium- or high-dose ICS-LABA treatment or that requires highdose ICS-LABA treatment to maintain good symptom control and reduce exacerbations.

Severe asthma is asthma that is uncontrolled despite good adherence with optimized high-dose ICS-LABA therapy and management of contributory factors or that worsens when high-dose treatment is decreased. Approximately $3-10 \%$ of people with asthma have severe asthma $(12,59)$.

Assess all patients with difficult-to-treat asthma to confirm the diagnosis of asthma and to identify and manage factors that commonly contribute to symptoms, poor quality of life, and/or exacerbations. For patients with persistent symptoms and/or exacerbations despite high-dose ICS-LABA, assess the clinical and inflammatory phenotype, as this may guide the selection of add-on treatment. Refer for expert advice if asthma does not improve in response to optimizing Step 4 or 5 treatment (or earlier, if needed).

\section{Management of Severe Asthma}

Refer patients to support services, where available, to help them deal with the heavy physical, emotional, social and financial burden of severe asthma and its treatment (60).
In Step 5, recommended add-on options include long-acting muscarinic antagonist (LAMA) (tiotropium $\geqslant 6 \mathrm{yr}$, triple therapy with ICS-LABA-LAMA $\geqslant 18 \mathrm{yr}$ ). Adding LAMA provided modest improvement in lung function but not symptom control, and exacerbations were reduced in some studies (61-65). Step 4 MART with ICS-formoterol should be tried before considering add-on LAMA; as-needed ICS-formoterol can be continued as the reliever for patients prescribed ICS-formoterol-LAMA, but for patients prescribed an ICS-LABA-LAMA with nonformoterol LABA, the appropriate reliever is SABA. After specialist referral, add-on, low-dose azithromycin is another option for reducing exacerbations, but risks of antibiotic resistance and prolongation of the corrected QT interval (QTc) on electrocardiography must be considered (66). Sputum-guided adjustment of the ICS dose improves outcomes in moderate-to-severe asthma (67) but is not widely available, and the optimal frequency of sputum assessment is not known.

With add-on biologic therapies for severe eosinophilic asthma (benralizumab, dupilumab, mepolizumab, reslizumab) and severe allergic asthma (dupilumab, omalizumab) the main benefits are substantial reduction in severe exacerbations and reduced OCS exposure (68). No headto-head studies are available, but typical eligibility criteria for each class, and predictors of good response, are found in the GINA pocket guide decision tree (13).

Maintenance OCS treatment should be avoided, wherever possible, because of its serious long-term side effects $(40,69)$.

At follow-up, assess the response to any add-on treatment, stop ineffective treatments, and consider other options. For patients who respond to add-on therapy, reevaluate the need for other therapies every 3-4 months, but do not completely stop ICS.

Continue to optimize patient care in collaboration with primary care and consider the patient's social and emotional needs. Arrange multidisciplinary team care for severe asthma, if available. Invite patients with severe asthma to enroll in a registry or clinical trial, if available and relevant, to help fill evidence gaps, including comparison of biologic therapy options and positioning of bronchial thermoplasty (68).

\section{Management of Worsening Asthma and Exacerbations}

Asthma exacerbations represent acute or subacute worsening in symptoms and lung function from the patient's usual status. In some cases, a patient may present for the first time during an exacerbation.

For discussion with patients, use terminology that is easily understood; "flareup" is more patient-friendly than the academic term "exacerbation." The terms "episodes," "attacks" and "acute asthma" are often used, but their meanings vary widely (70).

Preventing severe exacerbations that require treatment with systemic corticosteroids is an important goal of asthma management. Even a single OCS course has significant adverse effects (39), and taking as few as 4-5 courses of OCS over 7 years' follow-up is associated with increased risk of serious long-term conditions, including osteoporosis, pneumonia, cardiovascular disease, cataracts, renal impairment, diabetes, and weight gain $(40,69)$. Key strategies for reducing exacerbations include ICScontaining treatment (particularly asneeded-only ICS-formoterol and MART), managing risk factors, and providing a personalized written asthma action plan. The reduction in asthma exacerbations seen in many countries during the COVID-19 pandemic suggests that public health measures to reduce spread of severe acute respiratory syndrome coronavirus 2 (SARS-CoV-2) infections (e.g., handwashing, social/physical distancing, mask-wearing) may be important in reducing transmission of other respiratory viruses.

Patients at increased risk of asthmarelated death should be identified and reviewed more frequently. Factors include a history of requiring intubation and mechanical ventilation, having a hospitalization or emergency department (ED) visit for asthma in the previous year, not currently using or poorly adherent with ICS-containing therapy, overuse of SABAs (38), a history of psychiatric disease or psychosocial problems, concomitant food allergy, and currently using or having recently stopped OCS (a marker of exacerbation severity) (Box 4-1 in Reference 4). 


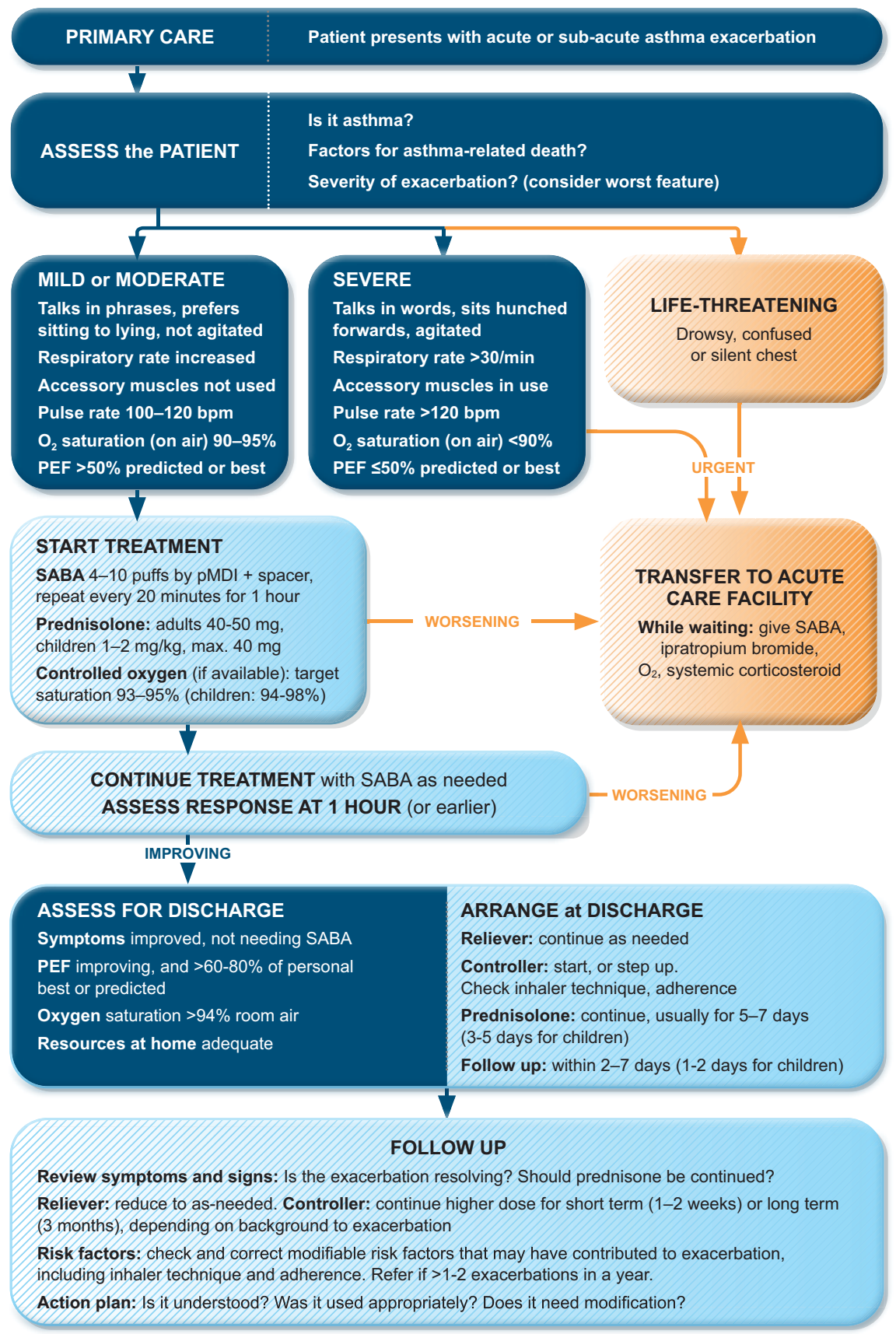

Figure 5. Management of asthma exacerbations in primary care (adults, adolescents, children 6-11 yr). SABA doses are for albuterol. Reproduced by permission from Reference 4 (Box 4-3). PEF = peak expiratory flow; pMDI = pressurized metered-dose inhaler; SABA = shortacting $\beta_{2}$-agonist.

\section{Written Asthma Action Plans}

As part of asthma self-management, provide all patients with a written asthma action plan appropriate for their level of asthma control and health literacy, so they know how to recognize and respond to worsening asthma (19). State when and how to change reliever and controller medications, use OCS if appropriate, and access medical care if symptoms fail to respond to treatment. Base the action plan on changes in symptoms or (only in adults) PEF (19).

Advise patients who have a history of rapid deterioration to go to an acute care facility or see their doctor immediately if their asthma starts to worsen.
Action plan recommendations for responding to worsening asthma depend on the patient's usual therapy. Patients prescribed as-needed ICS-formoterol as their reliever, either alone or in MART, should increase their as-needed doses as symptoms increase. Those on a maintenance ICScontaining controller should increase to a 


\section{Children 5 years and younger}

Personalized asthma management: Assess, Adjust, Review response

\section{Asthma medication options:}

Adjust treatment up and down for individual child's needs

\begin{tabular}{l|l|}
$\begin{array}{l}\text { PREFERRED } \\
\text { CONTROLLER } \\
\text { CHOICE }\end{array}$ & STEP 1 \\
\hline $\begin{array}{l}\text { Other } \\
\text { controller options }\end{array}$ & \\
\hline RELIEVER & \\
\hline $\begin{array}{l}\text { CONSIDER } \\
\text { THIS STEP FOR } \\
\text { CHILDREN WITH: }\end{array}$ & $\begin{array}{l}\text { Infrequent viral } \\
\text { wheezing and no } \\
\text { or few interval } \\
\text { symptoms }\end{array}$ \\
\hline
\end{tabular}

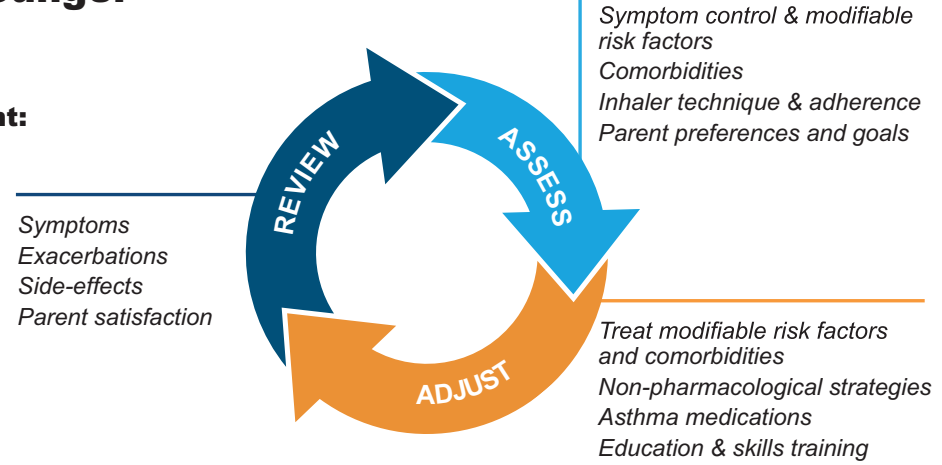

\section{STEP 2}

Daily low dose inhaled corticosteroid (ICS)

(see table of ICS dose ranges for pre-school children)

Daily leukotriene receptor antagonist (LTRA), or

intermittent short courses of ICS at onset of

respiratory illness
Exclude alternative diagnoses Symptom control \& modifiable risk factors

Inhaler technique \& adherence

Parent preferences and goals
Education \& skills training
Symptom pattern not consistent with asthma but wheezing episodes requiring SABA occur frequently, e.g. $\geq 3$ per year Give diagnostic trial for 3 months. Consider specialist referral. Symptom pattern consistent with asthma, and asthma symptoms not well-controlled or $\geq 3$ exacerbations per year.

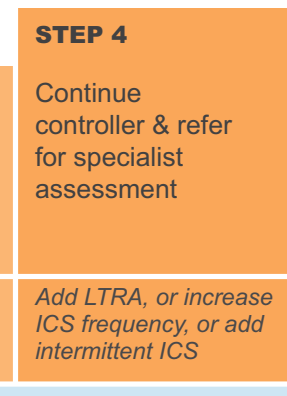

\section{STEP 3}

Double 'low dose' ICS

Low dose ICS + LTRA Consider specialist referral

Figure 6. Personalized management of asthma in children 5 years and younger. Reproduced by permission from Reference 4 (Box $6-5$ ). ICS = inhaled corticosteroid; LTRA = leukotriene receptor antagonist; SABA = short-acting $\beta_{2}$-agonist.

high dose temporarily (e.g., for 1-2 wk) (Box 4-2 in Reference 4).

Rationale. In a systematic review of self-management studies, action plans in which the ICS dose was at least doubled were associated with improved asthma outcomes and reduced healthcare use (71). In some studies in adults and adolescents $(19,72)$ and preschool children (73), short-term, higher-dose ICS reduced progression to a severe exacerbation, and some found less impact on serum cortisol than with OCS $(74,75)$, but cost may be an issue. Given the shape of the ICS dose-response curve, the benefit of increasing maintenance ICS when asthma worsens may be greater when background adherence is lower. The timing of an increased ICS dose may be important: studies in adults in which the ICS dose was doubled 5-7 days after symptoms worsened found no reduction in severe exacerbations $(76,77)$. In contrast, in MART, taking reliever doses of ICS-formoterol as soon as asthma symptoms occur, reduces the risk of progression to severe exacerbation $(24,25)$.

\section{Management of Exacerbations in a Primary Care or Acute Care Facility} Assess exacerbation severity from the patient's mental state, degree of dyspnea, vital signs, oxygen saturation, and lung function (PEF or spirometry) while starting treatment with repeated administration of SABA (in most patients, by pressurized metered-dose inhaler and spacer) and controlled flow oxygen (sufficient flow to maintain oxygen saturation at 93-95\% for adults; 94-98\% for children 6-11 yr), if available (Figure 5). Controlled oxygen therapy is associated with lower mortality and better outcomes than highconcentration (100\%) oxygen therapy (78-80).

Arrange immediate transfer to an acute care facility if there are signs of severe exacerbation, or to intensive care, particularly if the patient is drowsy, confused, or has a silent chest. During transfer, give inhaled SABA and ipratropium bromide, controlled oxygen, and systemic corticosteroids.

Repeated administration of albuterol (up to 4-10 puffs every $20 \mathrm{~min}$ for the first hour) is effective for rapidly reversing airflow limitation (81). Avoid nebulization except for lifethreatening asthma; delivery of rapid-acting $\beta_{2^{-}}$ agonist via a pressurized metered-dose inhaler and spacer or via a dry-powder inhaler is as effective in patients with moderately severe acute asthma $(81,82)$ and avoids the risk of disseminating infectious particles. Current evidence does not support the routine use of intravenous $\beta_{2}$-agonists in patients with severe asthma exacerbations (83).

Start OCS early after presentation. For adults, give prednisolone $40-50 \mathrm{mg} / \mathrm{d}$ (or equivalent) for 5-7 days. For children, give prednisolone $1-2 \mathrm{mg} / \mathrm{kg}$ (maximum, $40 \mathrm{mg}$ ) for 3-5 days. Tapering is not needed if administered for $<2$ weeks.

Review response of symptoms, vital signs, oxygen saturation and lung function after 1 hour (or earlier if worsening). Give ipratropium bromide only for severe exacerbations. Consider intravenous 
magnesium sulfate for patients with severe exacerbations not responding to initial treatment.

Do not routinely request chest radiography or routinely prescribe antibiotics for asthma exacerbations.

The decision on whether to hospitalize should be based on the patient's clinical status, lung function, response to treatment, recent and past history of exacerbations, social support, and ability to manage at home.

Rationale. Currently, inhaled albuterol is the usual bronchodilator in acute asthma management. Similar efficacy and safety of formoterol in the ED have been reported (84). In one study, high-dose budesonide-formoterol had similar efficacy and safety to SABA in ED patients (85).

\section{Discharge Management}

Before the patient goes home, arrange ongoing treatment. This should include starting ICS-containing controller treatment, preferably ICS-formoterol as MART (Table 1; Table E2 and downloadable resource in the online supplement) to reduce the risk of another exacerbation, or stepping up the dose of existing maintenance treatment for 2-4 weeks. Advise patients to use reliever medication as needed, not regularly. Patients prescribed ICS-formoterol as their reliever should return to this after an ED presentation.

\section{Follow-up}

Arrange early follow-up after any exacerbation, regardless of where it was managed:

- Review the patient's symptom control and risk factors for further exacerbations.

- $\quad$ Prescribe/continue ICS-containing controller therapy (preferably MART with ICS-formoterol) to reduce the risk of further exacerbations. If already taking controller therapy, continue increased doses for 2-4 weeks.

- Provide a written asthma action plan and, where relevant, advice about avoiding exacerbation triggers.

- Check inhaler technique and adherence.

Asthma outcomes after an ED presentation for acute asthma are significantly improved by comprehensive intervention programs that include optimal controller management, inhaler technique, and elements of self-management education (self-monitoring, written action plan, and regular review) $(86,87)$.

Referral for expert advice should be considered for patients who have been hospitalized for asthma or who have repeat presentations to acute care settings. Followup by a specialist is associated with fewer subsequent ED visits or hospitalizations and better asthma control (87).

\section{Diagnosis and Initial Treatment of Asthma in Children 5 Years and Younger}

\section{Diagnosis}

Recurrent wheezing occurs in a large proportion of children 5 years and younger, typically with viral respiratory infections. Recognizing when this is the initial presentation of asthma is difficult. In young children with a history of wheezing, a diagnosis of asthma is more likely if they have any of the following:

- Wheezing or coughing that occurs with exercise, laughing, or crying, particularly in the absence of an apparent respiratory infection.

- $\quad$ Allergic sensitization, eczema, allergic rhinitis or food allergy, or asthma in first-degree relatives.

- Clinical improvement during 2-3 months of controller treatment and worsening after cessation.

It is particularly important in this age group to consider and exclude alternative causes of wheeze, cough, and breathlessness (Box 6-3 in Reference 4).

Important indications for referral of children $\leqslant 5$ years for further diagnostic investigations include neonatal/very early onset of symptoms, failure to thrive, continuous wheezing, symptoms not associated with typical triggers (e.g., viral respiratory infections), or associated with vomiting, focal lung or cardiovascular signs, finger clubbing, hypoxemia outside the context of viral illness, or failure to respond to asthma medications.

\section{Initial Treatment}

The goals of asthma management in young children are to achieve good control of symptoms and maintain normal activity levels and to minimize the risk of asthma exacerbations, impaired lung development, and medication side effects.

Wheezing episodes in young children should be treated initially with inhaled SABA, regardless of whether the diagnosis of asthma has been made. However, SABAs are generally ineffective for initial episodes of wheeze in children younger than 1 year with infectious bronchiolitis.

A trial of controller therapy (e.g., for 3 mo) should be given if the symptom pattern suggests asthma, alternative diagnoses have been excluded, and respiratory symptoms are uncontrolled and/or wheezing episodes are frequent or severe (Figure 6). The response to treatment should be reviewed before deciding whether to continue it. If the response is absent or incomplete, reconsider alternative diagnoses.

It is important to discuss controller treatment choices with the child's parent/ caregiver to explain the relative benefits and risks of treatment and the importance of maintaining normal activity levels for their child's physical and social development.

The choice of inhaler device should be based on the child's age and capability. The preferred device is a pressurized metered-dose inhaler and spacer, with a face mask for children younger than 3 years and a mouthpiece for most aged 3-5 years. Children should be switched from a face mask to a mouthpiece as soon as they can demonstrate good technique.

Review the need for asthma treatment frequently, as asthma-like symptoms remit in many young children or may be markedly seasonal. Measure the child's height at least once every year.

\section{Asthma Treatment Steps for Children 5 Years and Younger}

\section{Step 1}

Provide inhaled SABA for relief of wheezing episodes. A need for SABA more than twice a week on average over 1 month indicates the need for a trial of controller medication.

\section{Step 2}

The preferred option is regular, daily, lowdose ICS plus as-needed SABA, given for at least 3 months (see Box 6-6 in Reference 4 for ICS doses). Regular montelukast is less effective than low-dose ICS, and parents/ 
caregivers should be counseled about potential neurobehavioral adverse effects, as in a boxed warning from the U.S. Food and Drug Administration (88).

\section{Step 3}

Before considering step-up to double the "low" ICS dose, check for concomitant or alternative diagnoses, check and correct inhaler technique and adherence, and ask about risk factors such as exposure to allergens or tobacco smoke. ICS-LABA is not recommended in children $<4$ years old, as there are insufficient data about efficacy and safety.

\section{Step 4}

Refer the child for expert advice if symptoms and/or flare-ups persist, or at any time if side effects of treatment are observed or suspected, or if there are doubts about diagnosis. See Chapter 6 in Reference 4 for details about other therapeutic options.

\section{Managing Exacerbations in Children 5 Years and Younger}

Early symptoms of exacerbations in young children may include increased symptoms, increased coughing (especially at night), lethargy or reduced exercise tolerance, impaired daily activities including feeding, and a poor response to reliever medication.

\section{Managing Exacerbations at Home}

Give a written asthma action plan to parents/ caregivers of young children with asthma so they can recognize an impending exacerbation, start treatment, and identify when urgent hospital treatment is required. Initial treatment at home is with inhaled SABA, with review after 1 hour or earlier. If inhaled SABA is needed more often than every 3 hours or for $>24$ hours, treatment by a health provider is needed on the same day. Parents/caregivers should seek urgent medical care if the child is acutely distressed, lethargic, fails to respond to initial bronchodilator therapy, or is worsening, especially in children younger than 1 year.

Rationale. Most children with wheezing due to asthma respond to SABA. There is insufficient evidence for parent-initiated OCS in this age group. Preemptive, episodic, parent-initiated high-dose nebulized ICS may reduce exacerbations in children with intermittent virally triggered wheezing (89), but there are no long-term studies, and there is a high risk of side effects; it should only be considered if the clinician is confident that it will be used appropriately and that the child will be monitored closely for side effects.

\section{Managing Exacerbations in Primary Care or Acute Care Facility}

Assess the severity of the exacerbation while initiating treatment with SABA (2-6 puffs every $20 \mathrm{~min}$ for first hour) and controlled oxygen to maintain a saturation of $94-98 \%$. Arrange immediate transfer to a hospital if the child shows no response to inhaled SABA within 1-2 hours, is unable to speak or drink, has a respiratory rate $>40 / \mathrm{min}$ or is cyanosed, has oxygen saturation $<92 \%$ on room air, or cannot be safely cared for at home.

For children attending an ED or admitted to hospital with asthma, consider systemic corticosteroids: oral prednisone/ prednisolone $1-2 \mathrm{mg} / \mathrm{kg} / \mathrm{d}$ for up to 5 days (maximum of $20 \mathrm{mg} / \mathrm{d}$ for children $0-2$ years and $30 \mathrm{mg} / \mathrm{d}$ for children 3-5 yr) or dexamethasone $0.6 \mathrm{mg} / \mathrm{kg} / \mathrm{d}$ for 2 days.

\section{Follow-up}

Children who have experienced an asthma exacerbation are at risk of further exacerbations. Arrange follow-up within 1-2 days of an exacerbation and again 1-2 months later to identify modifiable risk factors and exacerbation triggers, optimize ongoing asthma management, and check inhaler technique and adherence.

\section{Primary Prevention of Asthma in Children}

The development and persistence of asthma are driven by gene-environment interactions. For children, a "window of opportunity" to prevent asthma exists in utero and in early life, but intervention studies are limited. Current advice and recommendations for preventing asthma in children, based on high-quality evidence ( 90 , 91) or consensus, include the following:

- Avoid exposure to environmental tobacco smoke during pregnancy and after birth.

- Encourage vaginal delivery where possible.
- Where possible, avoid the use of acetaminophen and broad-spectrum antibiotics during the first year of life.

- Identification and correction of vitamin D insufficiency in women with asthma who are pregnant, or planning pregnancy, may reduce the risk of early-life wheezing episodes, but not asthma.

- $\quad$ Allergen avoidance strategies directed at a single allergen have not been effective in preventing asthma. Multifaceted strategies may be effective, but the essential components have not been identified.

Breast-feeding is advised for its general health benefits.

\section{Implementation of Asthma Management Strategies into Health Systems}

To improve asthma care and patient outcomes, evidence-based recommendations must be disseminated and implemented nationally and locally and integrated into health systems and clinical practice (92). Implementation requires an evidence-based strategy involving professional groups and stakeholders and considering local cultural and socioeconomic conditions. The costeffectiveness of implementation programs should be assessed so a decision can be made to pursue or modify them. Local adaptation and implementation of asthma care strategies are aided by purposedeveloped tools (92).

\section{Asthma Management in Low-Resource Settings}

GINA 2021 is a global strategy relevant to the care of all children, adolescents, and adults with asthma, wherever they live. Most of the global burden of asthma morbidity and mortality occurs in low-income and middleincome countries $(1,93)$ because of lack of necessary resources for effective long-term asthma care $(1,93,94)$. GINA has identified ongoing lack of access to ICS as a serious concern (4), especially as they can be produced at low cost. The safest and most effective approach to asthma treatment in adolescents and adults, which also avoids the 
consequences of starting treatment with SABA alone, depends on access to ICS-formoterol across all asthma severity levels (4). However, despite listing of budesonide-formoterol on WHO's Essential Medicines List (95), affordable access is very limited in many low-resource settings $(1,4$, $93,94,96)$. The urgent need to ensure access to affordable, quality-assured inhaled asthma medications as part of universal health coverage must now be prioritized by all relevant stakeholders, particularly manufacturers of inhalers on the WHO Essential Medicines List (95).

\section{Topics Requiring Further Research}

In addition to ongoing evidence reviews across the whole asthma strategy, GINA plans to review the following topics:

- The definition of mild asthma.

- Assessment of symptom control in patients whose reliever is ICS-formoterol.

- Subcutaneous and sublingual allergen immunotherapy.

- The diagnosis and management of asthma in preschool children.

- The use of digital tools and communication in asthma management.

- Management of asthma in low- and middle-income countries.

GINA also plans to develop a pocket guide for severe asthma in children 6-11 years. COVID-19 advice on the GINA website will be updated as new evidence emerges.
Author disclosures are available with the text of this article at www.atsjournals.org.

\begin{abstract}
Acknowledgment: The authors thank Rebecca Decker, GINA Executive Director, and Kristi Rurey, GINA Project Manager, for supporting and coordinating the GINA Science Committee and Board, Dr. Ruth Hadfield for assistance with literature research, GINA Advocates and Assembly members across many countries for identifying clinicians' needs and concerns, Kate Chisnall for assistance with graphics, and Jennifer Harman for editorial assistance. They thank Richard Beasley, Alan Kaplan, Hugo Neffen, Michael Schatz, Hesham Tarrif, and Richard van Zyl-Smit for their helpful review of the manuscript. They acknowledge the outstanding and dedicated work of $\mathrm{Dr}$. Suzanne Hurd as Scientific Director of GINA and Dr. Claude Lenfant as Executive Director, from the inception of GINA in 1993 until their retirement in 2015 .
\end{abstract}

\section{References}

1. Global Asthma Network. The global asthma report 2018. Auckland, New Zealand: Global Asthma Network; 2018 [accessed 2021 Sep]. Available from: http://globalasthmareport.org.

2. National Heart, Lung, and Blood Institute National Asthma Education and Prevention Program; World Health Organization. Global Initiative for Asthma. Bethesda, MD: National Institutes of Health; 1995. National Institutes of Health Publication No. 95-3659.

3. Global Initiative for Asthma. Methodology. Fontana, Wl: Global Initiative for Asthma; 2021 [accessed 2021 Sep]. Available from: https://ginasthma. org/about-us/methodology.

4. Global Initiative for Asthma. Global strategy for asthma management and prevention. Fontana, WI: Global Initiative for Asthma; 2021 [accessed 2021 Sep]. Available from: https://www.ginasthma.org/reports.

5. Aaron SD, Vandemheen KL, FitzGerald JM, Ainslie M, Gupta S, Lemière C, et al.; Canadian Respiratory Research Network. Reevaluation of diagnosis in adults with physician-diagnosed asthma. JAMA 2017;317: 269-279.

6. Reddel HK, Taylor DR, Bateman ED, Boulet LP, Boushey HA, Busse WW, et al.; American Thoracic Society/European Respiratory Society Task Force on Asthma Control and Exacerbations. An official American Thoracic Society/European Respiratory Society statement: asthma control and exacerbations: standardizing endpoints for clinical asthma trials and clinical practice. Am J Respir Crit Care Med 2009;180:59-99.

7. Schatz M, Kosinski M, Yarlas AS, Hanlon J, Watson ME, Jhingran P. The minimally important difference of the Asthma Control Test. J Allergy Clin Immunol 2009;124:719-23, e1.

8. Juniper EF, Svensson K, Mörk AC, Ståhl E. Measurement properties and interpretation of three shortened versions of the asthma control questionnaire. Respir Med 2005;99:553-558.

9. Dusser D, Montani D, Chanez P, de Blic J, Delacourt C, Deschildre A, et al. Mild asthma: an expert review on epidemiology, clinical characteristics and treatment recommendations. Allergy 2007;62: 591-604. [Published erratum appears in Allergy 62:968].

10. Pellegrino R, Viegi G, Brusasco V, Crapo RO, Burgos F, Casaburi R, et al. Interpretative strategies for lung function tests. Eur Respir J 2005; 26:948-968.

11. Barnes PJ, Szefler SJ, Reddel HK, Chipps BE. Symptoms and perception of airway obstruction in asthmatic patients: clinical implications for use of reliever medications. J Allergy Clin Immunol 2019;144:1180-1186.

12. Chung KF, Wenzel SE, Brozek JL, Bush A, Castro M, Sterk PJ, et al. International ERS/ATS guidelines on definition, evaluation and treatment of severe asthma. Eur Respir J 2014;43:343-373. [Published erratum appears in Eur Respir J 43:1216].

13. Global Initiative for Asthma. Difficult-to-treat and severe asthma in adolescent and adult patients: diagnosis and management. A GINA pocket guide for health professionals. Version 3. Fontana, WI Global Initiative for Asthma; 2021 [created 2021 Apr; accessed 2021 Sep]. Available from: https://www.ginasthma.org/reports.

14. Reddel HK, Busse WW, Pedersen S, Tan WC, Chen YZ, Jorup C, et al. Should recommendations about starting inhaled corticosteroid treatment for mild asthma be based on symptom frequency: a post-hoc efficacy analysis of the START study. Lancet 2017;389:157-166.

15. Beasley R, Holliday M, Reddel HK, Braithwaite I, Ebmeier S, Hancox RJ, et al.; Novel START Study Team. Controlled trial of budesonide-formoterol as needed for mild asthma. N Engl J Med 2019;380:2020-2030.

16. Hardy J, Baggott C, Fingleton J, Reddel HK, Hancox RJ, Harwood M, et al.; PRACTICAL Study Team. Budesonide-formoterol reliever therapy versus maintenance budesonide plus terbutaline reliever therapy in adults with mild to moderate asthma (PRACTICAL): a 52-week, open-label, multicentre, superiority, randomised controlled trial. Lancet 2019;394:919-928.

17. Agusti A, Bel E, Thomas M, Vogelmeier C, Brusselle G, Holgate S, et al. Treatable traits: toward precision medicine of chronic airway diseases. Eur Respir J 2016;47:410-419.

18. Pauwels RA, Pedersen S, Busse WW, Tan WC, Chen YZ, Ohlsson SV, et al.; START Investigators Group. Early intervention with budesonide in mild persistent asthma: a randomised, double-blind trial. Lancet 2003;361:1071-1076.

19. Pinnock H, Parke HL, Panagioti M, Daines L, Pearce G, Epiphaniou E, et al.; PRISMS and RECURSIVE Groups. Systematic meta-review of supported self-management for asthma: a healthcare perspective. BMC Med 2017;15:64

20. Suissa S, Ernst P, Kezouh A. Regular use of inhaled corticosteroids and the long term prevention of hospitalisation for asthma. Thorax 2002;57: 880-884.

21. O’Byrne PM, FitzGerald JM, Bateman ED, Barnes PJ, Zhong N, Keen C, et al. Inhaled combined budesonide-formoterol as needed in mild asthma. N Engl J Med 2018;378:1865-1876.

22. Suissa S, Ernst P, Benayoun S, Baltzan M, Cai B. Low-dose inhaled corticosteroids and the prevention of death from asthma. N Engl J Med 2000;343:332-336.

23. O'Byrne PM, Pedersen S, Lamm CJ, Tan WC, Busse WW; START Investigators Group. Severe exacerbations and decline in lung function in asthma. Am J Respir Crit Care Med 2009;179:19-24. 
24. Sobieraj DM, Weeda ER, Nguyen E, Coleman Cl, White CM, Lazarus $\mathrm{SC}$, et al. Association of inhaled corticosteroids and long-acting $\beta$-agonists as controller and quick relief therapy with exacerbations and symptom control in persistent asthma: a systematic review and metaanalysis. JAMA 2018;319:1485-1496.

25. Cates CJ, Karner C. Combination formoterol and budesonide as maintenance and reliever therapy versus current best practice (including inhaled steroid maintenance), for chronic asthma in adults and children. Cochrane Database Syst Rev 2013:CD007313.

26. Parsons JP, Hallstrand TS, Mastronarde JG, Kaminsky DA, Rundell KW, Hull JH, et al.; American Thoracic Society Subcommittee on Exerciseinduced Bronchoconstriction. An official American Thoracic Society clinical practice guideline: exercise-induced bronchoconstriction. $A m \mathrm{~J}$ Respir Crit Care Med 2013;187:1016-1027.

27. Lazarinis N, Jørgensen L, Ekström T, Bjermer L, Dahlén B, Pullerits T, et al. Combination of budesonide/formoterol on demand improves asthma control by reducing exercise-induced bronchoconstriction. Thorax 2014;69:130-136.

28. Reddel HK, FitzGerald JM, Bateman ED, Bacharier LB, Becker A, Brusselle G, et al. GINA 2019: a fundamental change in asthma management: treatment of asthma with short-acting bronchodilators alone is no longer recommended for adults and adolescents. Eur Respir J 2019;53:1901046.

29. Reddel HK, Ampon RD, Sawyer SM, Peters MJ. Risks associated with managing asthma without a preventer: urgent healthcare, poor asthma control and over-the-counter reliever use in a cross-sectional population survey. BMJ Open 2017;7:e016688.

30. Hancox RJ, Cowan JO, Flannery EM, Herbison GP, McLachlan CR, Taylor DR. Bronchodilator tolerance and rebound bronchoconstriction during regular inhaled beta-agonist treatment. Respir Med 2000;94: 767-771.

31. Cockcroft DW, McParland CP, Britto SA, Swystun VA, Rutherford BC. Regular inhaled salbutamol and airway responsiveness to allergen. Lancet 1993;342:833-837.

32. Pavord ID, Holliday M, Reddel HK, Braithwaite I, Ebmeier S, Hancox RJ, et al.; Novel START Study Team. Predictive value of blood eosinophils and exhaled nitric oxide in adults with mild asthma: a prespecified subgroup analysis of an open-label, parallel-group, randomised controlled trial. Lancet Respir Med 2020; 8:671-680.

33. Bateman ED, Reddel HK, O'Byrne PM, Barnes PJ, Zhong N, Keen C, et al. As-needed budesonide-formoterol versus maintenance budesonide in mild asthma. N Engl J Med 2018;378:1877-1887.

34. O’Byrne P, FitzGerald JM, Bateman ED, Barnes PJ, Zheng J, Gustafson $\mathrm{P}$, et al. Effect of a single day of increased as-needed budesonideformoterol use on short-term risk of severe exacerbations in patients with mild asthma: a post-hoc analysis of the SYGMA 1 study. Lancet Respir Med 2021;9:149-158.

35. Buhl R, Kuna P, Peters MJ, Andersson TL, Naya IP, Peterson S, et al. The effect of budesonide/formoterol maintenance and reliever therapy on the risk of severe asthma exacerbations following episodes of high reliever use: an exploratory analysis of two randomised, controlled studies with comparisons to standard therapy. Respir Res 2012;13:59.

36. Bousquet J, Boulet LP, Peters MJ, Magnussen H, Quiralte J, MartinezAguilar NE, et al. Budesonide/formoterol for maintenance and relief in uncontrolled asthma vs. high-dose salmeterol/fluticasone. Respir Med 2007;101:2437-2446.

37. Stanford RH, Shah MB, D'Souza AO, Dhamane AD, Schatz M. Shortacting $\beta$-agonist use and its ability to predict future asthma-related outcomes. Ann Allergy Asthma Immunol 2012;109:403-407.

38. Nwaru BI, Ekström M, Hasvold P, Wiklund F, Telg G, Janson C. Overuse of short-acting $\beta_{2}$-agonists in asthma is associated with increased risk of exacerbation and mortality: a nationwide cohort study of the global SABINA programme. Eur Respir J 2020;55:1901872.

39. Waljee AK, Rogers MA, Lin P, Singal AG, Stein JD, Marks RM, et al. Short term use of oral corticosteroids and related harms among adults in the United States: population based cohort study. BMJ 2017;357: j1415.

40. Price DB, Trudo F, Voorham J, Xu X, Kerkhof M, Ling Zhi Jie J, et al. Adverse outcomes from initiation of systemic corticosteroids for asthma: long-term observational study. J Asthma Allergy 2018;11:193-204.
41. Bårnes $\mathrm{CB}$, Ulrik CS. Asthma and adherence to inhaled corticosteroids: current status and future perspectives. Respir Care 2015;60:455-468.

42. Papi A, Canonica GW, Maestrelli P, Paggiaro P, Olivieri D, Pozzi E, et al.; BEST Study Group. Rescue use of beclomethasone and albuterol in a single inhaler for mild asthma. N Engl J Med 2007;356:2040-2052.

43. Calhoun WJ, Ameredes BT, King TS, Icitovic N, Bleecker ER, Castro M, et al.; Asthma Clinical Research Network of the National Heart, Lung, and Blood Institute. Comparison of physician-, biomarker-, and symptom-based strategies for adjustment of inhaled corticosteroid therapy in adults with asthma: the BASALT randomized controlled trial. JAMA 2012;308:987-997.

44. Martinez FD, Chinchilli VM, Morgan WJ, Boehmer SJ, Lemanske RF Jr, Mauger DT, et al. Use of beclomethasone dipropionate as rescue treatment for children with mild persistent asthma (TREXA): a randomised, double-blind, placebo-controlled trial. Lancet 2011;377: 650-657.

45. Sumino K, Bacharier LB, Taylor J, Chadwick-Mansker K, Curtis V, Nash A, et al. A pragmatic trial of symptom-based inhaled corticosteroid use in African-American children with mild asthma. $J$ Allergy Clin Immunol Pract 2020;8:176-185, e2.

46. Demoly P, Louis R, Søes-Petersen U, Naya I, Carlsheimer A, Worth H, et al. Budesonide/formoterol maintenance and reliever therapy versus conventional best practice. Respir Med 2009;103:1623-1632.

47. Vogelmeier C, D'Urzo A, Pauwels R, Merino JM, Jaspal M, Boutet S, et al. Budesonide/formoterol maintenance and reliever therapy: an effective asthma treatment option? Eur Respir J 2005;26: 819-828.

48. Patel M, Pilcher J, Pritchard A, Perrin K, Travers J, Shaw D, et al.; SMART Study Group. Efficacy and safety of maintenance and reliever combination budesonide-formoterol inhaler in patients with asthma at risk of severe exacerbations: a randomised controlled trial. Lancet Respir Med 2013;1:32-42.

49. Papi A, Corradi M, Pigeon-Francisco C, Baronio R, Siergiejko Z, Petruzzelli S, et al. Beclometasone-formoterol as maintenance and reliever treatment in patients with asthma: a double-blind, randomised controlled trial. Lancet Respir Med 2013;1:23-31.

50. Bateman ED, Harrison TW, Quirce S, Reddel HK, Buhl R, Humbert M, et al. Overall asthma control achieved with budesonide/formoterol maintenance and reliever therapy for patients on different treatment steps. Respir Res 2011;12:38.

51. Jorup C, Lythgoe D, Bisgaard H. Budesonide/formoterol maintenance and reliever therapy in adolescent patients with asthma. Eur Respir $J$ 2018;51:1701688.

52. Bisgaard H, Le Roux P, Bjåmer D, Dymek A, Vermeulen JH, Hultquist C. Budesonide/formoterol maintenance plus reliever therapy: a new strategy in pediatric asthma. Chest 2006;130:1733-1743.

53. Stempel DA, Szefler SJ, Pedersen S, Zeiger RS, Yeakey AM, Lee LA, et al.; VESTRI Investigators. Safety of adding salmeterol to fluticasone propionate in children with asthma. N Engl J Med 2016;375:840-849.

54. Murphy VE, Gibson PG. Asthma in pregnancy. Clin Chest Med 2011;32: 93-110.

55. Global Initiative for Chronic Obstructive Lung Disease. Global strategy for diagnosis, management and prevention of COPD. Fontana, WI: Global Initiative for Chronic Obstructive Lung Disease; 2021 [accessed 2021 Sep]. Available from: https://goldcopd.org/.

56. Gershon AS, Campitelli MA, Croxford R, Stanbrook MB, To T, Upshur R, et al. Combination long-acting $\beta$-agonists and inhaled corticosteroids compared with long-acting $\beta$-agonists alone in older adults with chronic obstructive pulmonary disease. JAMA 2014;312:1114-1121.

57. Suissa S, Ernst P. Observational studies of inhaled corticosteroid effectiveness in COPD: lessons learned. Chest 2018;154:257-265.

58. Kendzerska T, Aaron SD, To T, Licskai C, Stanbrook M, Vozoris NT, et al. Effectiveness and safety of inhaled corticosteroids in older individuals with chronic obstructive pulmonary disease and/or asthma: a population study. Ann Am Thorac Soc 2019;16:1252-1262.

59. Hekking PW, Wener RR, Amelink M, Zwinderman AH, Bouvy ML, Bel $\mathrm{EH}$. The prevalence of severe refractory asthma. J Allergy Clin Immunol 2015;135:896-902.

60. Foster JM, McDonald VM, Guo M, Reddel HK. "I have lost in every facet of my life": the hidden burden of severe asthma. Eur Respir J 2017;50: 1700765. 
61. Kerstjens HAM, Maspero J, Chapman KR, van Zyl-Smit RN, Hosoe M, Tanase AM, et al.; IRIDIUM Trial Investigators. Once-Daily, SingleInhaler Mometasone-Indacaterol-Glycopyrronium versus MometasoneIndacaterol or Twice-Daily Fluticasone-Salmeterol in Patients with Inadequately Controlled Asthma (IRIDIUM): a randomised, doubleblind, controlled phase 3 study. Lancet Respir Med 2020;8:1000-1012.

62. Virchow JC, Kuna P, Paggiaro P, Papi A, Singh D, Corre S, et al. Single inhaler extrafine triple therapy in uncontrolled asthma (TRIMARAN and TRIGGER): two double-blind, parallel-group, randomised, controlled phase 3 trials. Lancet 2019;394:1737-1749.

63. Lee LA, Bailes Z, Barnes N, Boulet LP, Edwards D, Fowler A, et al. Efficacy and safety of once-daily single-inhaler triple therapy (FF/ $\mathrm{UMEC} / \mathrm{VI}$ ) versus $\mathrm{FF} / \mathrm{VI}$ in patients with inadequately controlled asthma (CAPTAIN): a double-blind, randomised, phase 3A trial. Lancet Respir Med 2021;9:69-84.

64. Casale TB, Aalbers R, Bleecker ER, Meltzer EO, Zaremba-Pechmann L, de la Hoz A, et al. Tiotropium Respimat ${ }^{\circledR}$ add-on therapy to inhaled corticosteroids in patients with symptomatic asthma improves clinical outcomes regardless of baseline characteristics. Respir Med 2019;158: 97-109.

65. Sobieraj DM, Baker WL, Nguyen E, Weeda ER, Coleman CI, White CM, et al. Association of inhaled corticosteroids and long-acting muscarinic antagonists with asthma control in patients with uncontrolled, persistent asthma: a systematic review and meta-analysis. JAMA 2018;319: 1473-1484.

66. Hiles SA, McDonald VM, Guilhermino M, Brusselle GG, Gibson PG. Does maintenance azithromycin reduce asthma exacerbations? An individual participant data meta-analysis. Eur Respir J 2019;54:1901381.

67. Petsky HL, Li A, Chang AB. Tailored interventions based on sputum eosinophils versus clinical symptoms for asthma in children and adults. Cochrane Database Syst Rev 2017:CD005603.

68. Holguin F, Cardet JC, Chung KF, Diver S, Ferreira DS, Fitzpatrick A, et al. Management of severe asthma: a European Respiratory Society/ American Thoracic Society guideline. Eur Respir J 2020;55:1900588.

69. Lefebvre P, Duh MS, Lafeuille MH, Gozalo L, Desai U, Robitaille MN, et al. Acute and chronic systemic corticosteroid-related complications in patients with severe asthma. J Allergy Clin Immunol 2015;136: 1488-1495.

70. Blaiss MS, Nathan RA, Stoloff SW, Meltzer EO, Murphy KR, Doherty DE. Patient and physician asthma deterioration terminology: results from the 2009 Asthma Insight and Management Survey. Allergy Asthma Proc 2012:33:47-53.

71. Gibson PG, Powell H. Written action plans for asthma: an evidencebased review of the key components. Thorax 2004;59:94-99.

72. McKeever T, Mortimer K, Wilson A, Walker S, Brightling C, Skeggs A, et al. Quadrupling inhaled glucocorticoid dose to abort asthma exacerbations. N Engl J Med 2018;378:902-910.

73. Ducharme FM, Lemire C, Noya FJ, Davis GM, Alos N, Leblond H, et al. Preemptive use of high-dose fluticasone for virus-induced wheezing in young children. N Engl J Med 2009;360:339-353.

74. van den Berge M, Arshad SH, Ind PW, Magnussen H, Hamelmann E, Kanniess $F$, et al. Similar efficacy of ciclesonide versus prednisolone to treat asthma worsening after steroid tapering. Respir Med 2009;103: 1216-1223.

75. Wilson AM, Lipworth BJ. Short-term dose-response relationships for the relative systemic effects of oral prednisolone and inhaled fluticasone in asthmatic adults. Br J Clin Pharmacol 1999;48:579-585.

76. FitzGerald JM, Becker A, Sears MR, Mink S, Chung K, Lee J; Canadian Asthma Exacerbation Study Group. Doubling the dose of budesonide versus maintenance treatment in asthma exacerbations. Thorax 2004; 59:550-556.

77. Harrison TW, Oborne J, Newton S, Tattersfield AE. Doubling the dose of inhaled corticosteroid to prevent asthma exacerbations: randomised controlled trial. Lancet 2004;363:271-275.

78. Perrin K, Wijesinghe M, Healy B, Wadsworth K, Bowditch R, Bibby S, et al. Randomised controlled trial of high concentration versus titrated oxygen therapy in severe exacerbations of asthma. Thorax 2011;66: 937-941.

79. Patel B, Khine H, Shah A, Sung D, Medar S, Singer L. Randomized clinical trial of high concentration versus titrated oxygen use in pediatric asthma. Pediatr Pulmonol 2019;54:970-976.

80. Siemieniuk RAC, Chu DK, Kim LH, Güell-Rous MR, Alhazzani W, Soccal PM, et al. Oxygen therapy for acutely ill medical patients: a clinical practice guideline. BMJ 2018;363:k4169.

81. Cates CJ, Welsh EJ, Rowe BH. Holding chambers (spacers) versus nebulisers for beta-agonist treatment of acute asthma. Cochrane Database Syst Rev 2013:CD000052.

82. Selroos O. Dry-powder inhalers in acute asthma. Ther Deliv 2014;5: 69-81.

83. Travers AH, Milan SJ, Jones AP, Camargo CA Jr, Rowe BH. Addition of intravenous beta -agonists to inhaled beta $_{2}$-agonists for acute asthma. Cochrane Database Syst Rev 2012:CD010179.

84. Rodrigo GJ, Neffen H, Colodenco FD, Castro-Rodriguez JA. Formoterol for acute asthma in the emergency department: a systematic review with meta-analysis. Ann Allergy Asthma Immunol 2010;104:247-252.

85. Balanag VM, Yunus F, Yang PC, Jorup C. Efficacy and safety of budesonide/formoterol compared with salbutamol in the treatment of acute asthma. Pulm Pharmacol Ther 2006;19:139-147.

86. Gibson PG, Powell H, Coughlan J, Wilson AJ, Abramson M, Haywood $P$, et al. Self-management education and regular practitioner review for adults with asthma. Cochrane Database Syst Rev 2003: CD001117.

87. Schatz M, Rachelefsky G, Krishnan JA. Follow-up after acute asthma episodes: what improves future outcomes? Proc Am Thorac Soc 2009, 6:386-393.

88. U.S. Food and Drug Administration. FDA requires boxed warning about serious mental health side effects for asthma and allergy drug montelukast (Singulair); advises restricting use for allergic rhinitis. Silver Spring, MD: U.S. Food and Drug Administration; 2020 [accessed 2021 Sep]. Available from: https://www.fda.gov/drugs/drug-safety-andavailability/fda-requires-boxed-warning-about-serious-mental-healthside-effects-asthma-and-allergy-drug

89. Kaiser SV, Huynh T, Bacharier LB, Rosenthal JL, Bakel LA, Parkin PC, et al. Preventing exacerbations in preschoolers with recurrent wheeze: a meta-analysis. Pediatrics 2016;137:e20154496.

90. Brożek JL, Bousquet J, Baena-Cagnani CE, Bonini S, Canonica GW, Casale TB, et al.; Global Allergy and Asthma European Network; Grading of Recommendations Assessment, Development and Evaluation Working Group. Allergic rhinitis and its impact on asthma (ARIA) guidelines: 2010 revision. J Allergy Clin Immunol 2010;126: 466-476.

91. Beasley R, Semprini A, Mitchell EA. Risk factors for asthma: is prevention possible? Lancet 2015;386:1075-1085.

92. Boulet LP, FitzGerald JM, Levy ML, Cruz AA, Pedersen S, Haahtela T, et al. A guide to the translation of the Global Initiative for Asthma (GINA) strategy into improved care. Eur Respir J 2012;39:1220-1229.

93. Meghji J, Mortimer K, Agusti A, Allwood BW, Asher I, Bateman ED, et al. Improving lung health in low-income and middle-income countries: from challenges to solutions. Lancet 2021;397:928-940.

94. Asher I, Bissell K, Chiang CY, El Sony A, Ellwood P, García-Marcos L, et al. Calling time on asthma deaths in tropical regions-how much longer must people wait for essential medicines? Lancet Respir Med 2019;7:13-15.

95. World Health Organization. WHO model lists of essential medicines. Geneva, Switzerland: World Health Organization; 2021 [accessed 2021 Sep]. Available from: https://www.who.int/groups/expert-committee-onselection-and-use-of-essential-medicines/essentialmedicines-lists.

96. Sanyang B, Jagne E, Sefa N, Touray S. Availability, cost, and affordability of asthma and chronic obstructive pulmonary disease medications in The Gambia. J Pan Afr Thorac Soc 2021;2:33-41. 